\title{
Clinical Practice Guideline for the Diagnosis and Treatment of Pediatric Obesity: Recommendations from the Committee on Pediatric Obesity of the Korean Society of Pediatric Gastroenterology Hepatology and Nutrition
}

Dae Yong Yi, Soon Chul Kim*, Ji Hyuk Lee ${ }^{\dagger}$, Eun Hye Lee ${ }^{\ddagger}$, Jae Young Kim ${ }^{\S}$, Yong Joo Kim $\|$ Ki Soo Kang, Jeana Hong ${ }^{* *}$, Jung Ok Shim ${ }^{t^{\dagger}, \neq \neq}$, Yoon Lee ${ }^{\neq \neq}$, Ben Kang ${ }^{\S \S}$, Yeoun Joo Lee $\|^{\prime \prime}$, Mi Jin Kim ${ }^{\uparrow,}$, Jin Soo Moon***, Hong Koh ${ }^{\dagger \dagger \dagger}$, JeongAe You ${ }^{\ddagger \neq}{ }^{\ddagger}$, Young-Sook Kwak ${ }^{\S \S \S}$, Hyunjung Lim "I II, and Hye Ran Yang

Department of Pediatrics, Chung-Ang University Hospital, Chung-Ang University, College of Medicine, Seoul, "Department of Pediatrics, Chonbuk National University Hospital, Chonbuk National University Medical School, Jeonju, ${ }^{\dagger}$ Department of Pediatrics, Chungbuk National University College of Medicine, Chungju, ${ }^{7}$ Department of Pediatrics, Nowon Eulji Medical Center, Eulji University School of Medicine, Seoul, ${ }^{\mathcal{S}}$ Department of Pediatrics, Gyeongsang National University Changwon Hospital, Changwon, "Department of Pediatrics, Hanyang University College of Medicine, Seoul, "Department of Pediatrics, Jeju National University Hospital, Jeju, ${ }^{* *}$ Department of Pediatrics, Kangwon National University School of Medicine, Chuncheon, ${ }^{+{ }^{+}}$Department of Pediatrics, Korea University Guro Hospital, Seoul, ${ }^{\neq \neq}$Department of Pediatrics, Korea University College of Medicine, Seoul, ${ }^{\text {SS }}$ Department of Pediatrics, School of Medicine, Kyungpook National University, Daegu, "I" Department of Pediatrics, Pusan National University Children's Hospital, Pusan National University School of Medicine, Yangsan, "Department of Pediatrics, Samsung Medical Center, Sungkyunkwan University School of Medicine, ${ }^{* * *}$ Department of Pediatrics, Seoul National University Children's Hospital, Seoul National University College of Medicine, ${ }^{+{ }^{+t}}$ Department of Pediatrics, Severance Children's Hospital, Yonsei University College of Medicine, ${ }^{\text {ff }}$ Department of Physical Education, College of Education, Chung-Ang University, Seoul, ${ }^{S S S}$ Department of Psychiatry, Jeju National University Hospital, Jeju, "II " Department of Medical Nutrition, Kyung Hee University, Seoul, ${ }^{M(T /}$ Department of Pediatrics, Seoul National University Bundang Hospital, Seongnam, ${ }^{* * * *}$ Department of Pediatrics, Seoul National University College of Medicine, Seoul, Korea

The Committee on Pediatric Obesity of the Korean Society of Pediatric Gastroenterology, Hepatology and Nutrition newly developed the first Korean Guideline on the Diagnosis and Treatment of Obesity in Children and Adolescents to deliver an evidence-based systematic approach to childhood obesity in South Korea. The following areas were systematically reviewed, especially on the basis of all available references published in South Korea and worldwide,

Received : November 29, 2018, Revised : December 11, 2018, Accepted : December 12, 2018

Corresponding author: Hye Ran Yang, Division of Pediatric Gastroenterology, Hepatology and Nutrition, Department of Pediatrics, Seoul National University Bundang Hospital, 82 Gumi-ro, 173beon-gil, Bundang-gu, Seongnam 13620, Korea. Tel: +82-31-787-7285, Fax: +82-31-787-4054, E-mail: hryang@snubh.org

This article has been published simultaneously in Pediatric Gastroenterology, Hepatology \& Nutrition and Korean Journal of Pediatrics by the permission of editor-in-chief of two journals.

Copyright (c) 2019 by The Korean Society of Pediatric Gastroenterology, Hepatology and Nutrition

This is an open-access article distributed under the terms of the Creative Commons Attribution Non-Commercial License (http://creativecommons.org/licenses/by-nc/4.0/) which permits unrestricted non-commercial use, distribution, and reproduction in any medium, provided the original work is properly cited. 
and new guidelines were established in each area with the strength of recommendations based on the levels of evidence: 1) definition and diagnosis of overweight and obesity in children and adolescents; 2) principles of treatment of pediatric obesity; 3) behavioral interventions for children and adolescents with obesity, including diet, exercise, lifestyle, and mental health; 4) pharmacotherapy; and 5) bariatric surgery.

Key Words: Guideline, Obesity, Diagnosis, Treatment, Child

\section{INTRODUCTION}

The prevalence of childhood obesity is dramatically increasing in South Korea, which has been associated with changes in lifestyle, such as Westernized high-calorie, high-fat diet with sugar-sweetened beverages, sedentary lifestyles, and decreased physical activity [1]. In a recent report, the prevalence of obesity in children aged below 6 years increased from $1.4 \%$ in 2008 to $2.8 \%$ in 2015 , and that in children and adolescents aged 7 to 18 years rapidly increased from $8.4 \%$ in 2008 to $14.3 \%$ in 2016 [1]. Accordingly, the prevalence of obesity-related physical, psychosocial, and metabolic complications, such as metabolic syndrome and non-alcoholic fatty liver disease (NAFLD), is also increasing in Korean children and adolescents [2].

Childhood obesity may persist lifelong if not treated properly; it can lead to adulthood obesity and a variety of metabolic and cardiovascular complications later in life. Thus, pediatric obesity is regarded as one of the priority health issues, and the treatment of childhood obesity and its complications may be one of the most effective strategies to reducing morbidities and mortalities and to saving hospital costs later in life.

Strict guidelines or consensus statements on the diagnosis and treatment of pediatric obesity have been published and updated in Western countries. However, to date, there are no evidence-based guidelines on pediatric obesity in Asia, including South Korea. Therefore, the Committee on Pediatric Obesity of the Korean Society of Pediatric Gastroen- terology, Hepatology and Nutrition (KSPGHAN) developed an evidence-based guideline on the diagnosis and treatment of obesity in children and adolescents, to deliver a systematic approach to childhood obesity in South Korea.

\section{METHODS}

To develop the first evidence-based clinical practice guideline on the diagnosis and treatment of obesity in children and adolescents in South Korea, the Committee on Pediatric Obesity of the KSPGHAN established a Guideline Task Force (TF) in March 2017. This TF was composed of pediatric gastroenterologists with an expertise in clinical nutrition, as well as pediatric neuropsychiatrists, clinical nutrition specialists, and exercise specialists. Experts from these areas were designated to each TF subgroup according to their professional specialty.

A systematic protocol for the establishment of an evidence-based guideline for the diagnosis and treatment of obesity in children and adolescents was prepared and established through regular TF meetings. The basic format of the guideline was determined to encompass a total of eight topics within five different sections as follows:

1) Definition and diagnosis of overweight and obesity in children and adolescents

2) Principles of the treatment of pediatric obesity

3) Behavioral interventions for children and adolescents with obesity

(1) Diet

(2) Exercise 
(3) Lifestyle

(4) Mental health

4) Pharmacotherapy in children and adolescents with obesity

5) Bariatric surgery in children and adolescents with obesity

Each TF working subgroup searched all references related to pediatric obesity in each assigned field through PubMed search using MeSH (Medical Subject Headings) terms, as well as all available references published in South Korea using appropriate systematic search strategies. These references included randomized controlled trials (RCTs), observational studies (e.g., case-control studies, prospective and retrospective cohort studies, case series studies), meta-analyses, systematic reviews, and previous obesity guidelines or position papers or consensuses on both children and adults with obesity through the entire period using a last search date of September 30, 2018. Subsequently, each TF subgroup reviewed, analyzed, and summarized all related documents and references in each field.

To establish a systematic evidence-based guideline, the strength of evidence and grade of recommendation were determined for each recommendation according to a previously adapted classification system for evidence-based guidelines (Table 1) [3-5]. The strength of evidence was classified from level I to level $\mathrm{V}$ based on the value of the evidence in the literature, including systematic review, meta-analysis, and scientific papers: RCTs, well-designed trials, consensus studies, and opinions of research groups, respected authorities, and expert committees. Level I represents the strongest evidence.

The grade of recommendation was determined according to the strength of evidence and importance of the recommendation. Levels I to III evidence were decided to correspond to Grades A to C of recommendations, which were regarded as highly recommended or recommended, respectively. Levels IV and $\mathrm{V}$ recommendations for were basically regarded as Grade D; the final grade was decided through voting consensus of the entire TF. A total of three face-to-face meetings were held in Seoul and Jeju Island and 14 online video meetings to achieve consensus on all of the recommendations. All recommendations were voted on and accepted when $100 \%$ agreement was achieved.

\section{Definition and diagnosis of overweight and obesity in children and adolescents}

1-1. We suggest to use the Korean National Growth Charts body mass index (BMI) percentile to diagnose overweight and obesity in children and adolescents over two years of age. (Strength of evidence, level III; grade of recommendation, C)

1-2. We suggest to diagnose overweight when the BMI is above the 85 th but $<95$ th percentile for age and sex, and obesity when the BMI is above the 95th percentile in children and adolescents $>2$ years of age. (Strength of evidence, III; grade of recommendation, C)

1-3. We suggest that children $<24$ months of age be diagnosed as overweight if weight for height is above the 95th percentile on the Korean National Growth Charts, which introduced the World Health Organization (WHO) growth standards in this age group, as the Korean Society of Pediatrics accepts this basis as valid. (Strength of evidence, V; grade of recommendation, $\mathrm{C}$, based on committee voting) 1-4. We recommend to assess comorbidities: NAFLD, dyslipidemia, hypertension, prediabetes, type II diabetes mellitus (DM), polycystic ovary syndrome, obstructive sleep apnea, and psychosocial problems. (Strength of evidence, V; grade of recommendation, A, based on committee voting)

1-1. We suggest to use the Korean National Growth Charts BMI percentile to diagnose overweight and obesity in children and adolescents over two years of age. (Strength of evidence, level III; grade of recommendation, C)

The Korean National Growth BMI charts are accepted as valid for Korean children and adolescents over two years of age and provide a means for de- 
Table 1. The Strength of Evidence and the Grade of Recommendation in Support of the Recommendations Formulated and Established in the KSPGHAN Clinical Practice Guideline on the Diagnosis and Treatment of Pediatric Obesity [5]

\begin{tabular}{|c|c|c|c|}
\hline $\begin{array}{l}\text { Strength of } \\
\text { evidence }\end{array}$ & $\begin{array}{l}\text { Grade of } \\
\text { recommendation }\end{array}$ & & \\
\hline I & Grade A & $\begin{array}{l}\text { Strong evidence from one or more systematic review(s) of } \\
\text { well-designed RCTs }\end{array}$ & Highly recommended \\
\hline II & Grade B & $\begin{array}{l}\text { Strong evidence from one or more properly designed RCT(s) of } \\
\text { appropriate size }\end{array}$ & Recommended \\
\hline III & Grade $\mathrm{C}$ & $\begin{array}{l}\text { Evidence from well-designed clinical trials without randomization, } \\
\text { comparative study in a single group, cohort study, time series } \\
\text { study or matched case-control studies }\end{array}$ & Recommended \\
\hline IV & Grade D & $\begin{array}{l}\text { Evidence from well-designed clinical trials, non-experimental } \\
\text { studies from one or more center or research group }\end{array}$ & $\begin{array}{l}\text { The consensus route would } \\
\text { have to be adopted }\end{array}$ \\
\hline V & Grade D & $\begin{array}{l}\text { Opinion of respected authorities, clinical evidence, descriptive } \\
\text { studies, or reports of experts committees }\end{array}$ & $\begin{array}{l}\text { The consensus route would } \\
\text { have to be adopted }\end{array}$ \\
\hline
\end{tabular}

KSPGHAN: Korean Society of Pediatric Gastroenterology Hepatology and Nutrition, RCT: randomized controlled trial.

termining changes in pediatric obesity prevalence [6]. The 2017 Korean National Growth Charts are recommended for the evaluation of body size and growth of Korean children and adolescents to use in practice and in the public health sector in South Korea [6].

A systematic review by the United States Preventive Services TF reported that the BMI of children and adolescents correlate well to the percentile of body fat [7]. In 1990s, an expert committee recommended using BMI for screening overweight in children and adolescents [8]. In the 2000 Centers for Disease Control (CDC) Growth Chart and 2011 United Kingdom (UK) Growth Chart (http://www.rcpch.ac.uk/growthcharts), the BMI chart is available for children and adolescents aged 2 to 20 years [9]. Meanwhile, a considerable proportion of boys and girls with relatively normal fat mass appear to be misclassified and may be at risk of being overweight based on the BMI criteria in a Korean study using the Korea National Health and Nutrition Examination Survey; their findings indicated that body fat mass and fat-free mass would be helpful for complementary assessment [10]. Despite some limitations, BMI is currently the most reasonable method for diagnosing overweight and obesity in children over two years old.
1-2. We suggest to diagnose overweight when the BMl is above the 85th but <95th percentile for age and sex, and obesity when the BMI is above the 95th percentile in children and adolescents $>$ two years of age. (Strength of evidence, III; grade of recommendation, C)

$1-3$. We suggest that children $<24$ months of age be diagnosed as overweight if weight for height is above the 95th percentile on the Korean National Growth Charts, which introduced the WHO growth standards in this age group, as the Korean Society of Pediatrics has accepted this standard as valid. (Strength of evidence, V; grade of recommendation, $C$, based on committee voting)

The Korean National Growth Chart recently revised the BMI cutoffs of obesity in children and adolescents. The criteria of obesity for children aged $>2$ years have changed from a BMI of $\geq 95$ th percentile for age and sex or BMI $\geq 25 \mathrm{~kg} / \mathrm{m}^{2}$ to a BMI of $\geq 95$ th percentile for age and sex [6]. When applying a new BMI cutoff and a recently developed Korean National Growth Chart, a study reported that the prevalence of obesity is $10.3 \%$ in South Korea [6]. These criteria, based on the BMI percentiles, are the same as those used in United States of America (US), based on the CDC Growth Chart, and in the UK (http://www.rcpch.ac.uk/growthcharts) [9,11]. We could not find any meta-analysis or systematic re- 
view to justify applying the adult standards of BMI $\geq 25 \mathrm{~kg} / \mathrm{m}^{2}$ to children, regardless of risk evaluations of comorbidities. In children aged under two years, the criteria of overweight were changed from weight for age to weight for height in a recent 2017 Korean Growth Chart after the introduction of the WHO Child Growth Standards [12].

Data suggest that severely obese children and adolescents have a worse risk factor profile compared with less obese children. In a large cross-sectional and longitudinal study in the US, 59\% of children with BMI $\geq 99$ th percentile had at least two risk factors, whereas $39 \%$ of children with BMI $\geq 95$ th percentile had at least two risk factors [13]. Consequently, expert committees in the US and Italy have suggested BMI 299 th percentile as severe obesity in older children [14,15]. In another proposed US guideline, extreme or class 2 obesity in children is defined as a BMI exceeding $120 \%$ of the 95 th percentile or $>35 \mathrm{~kg} / \mathrm{m}^{2}$, and class 3 obesity to be BMI exceeding $140 \%$ of the 95 th percentile or $>40 \mathrm{~kg} / \mathrm{m}^{2}$ [11].

WHO provides the values of BMI as $\geq 99$ th percentile and +3 standard deviations of $Z$ scores [16]. The WHO definition for severe obesity differs between age groups. The 99th percentile identifies "obesity" in the younger age group (0-5 years) and "severe obesity" in the older age group ( $5-18$ years). This approach takes into account the difference in growth process between younger and older children. Few data are available on the significance of the cutoffs for the upper end of the BMI in preschool-aged children. Moreover, the WHO cutoffs for severe obesity have not been assessed yet.

The Korean Growth Chart also provides the curves of BMI $\geq 99$ th percentile and +3 standard deviations of $Z$ scores in its website (http://www.cdc.go.kr/).

1-4. We recommend to assess comorbidities: NAFLD, dyslipidemia, hypertension, prediabetes, type II DM, polycystic ovary syndrome, obstructive sleep apnea, and psychosocial problems. (Strength of evidence, $\mathrm{V}$; grade of recommendation, $\mathrm{A}$, based on committee voting)

In obese children and adolescents, the assessment for comorbidities is recommended (Fig. 1). Table 2 lists the suggested obesity-related comorbidities and their corresponding screening tests [17-22].

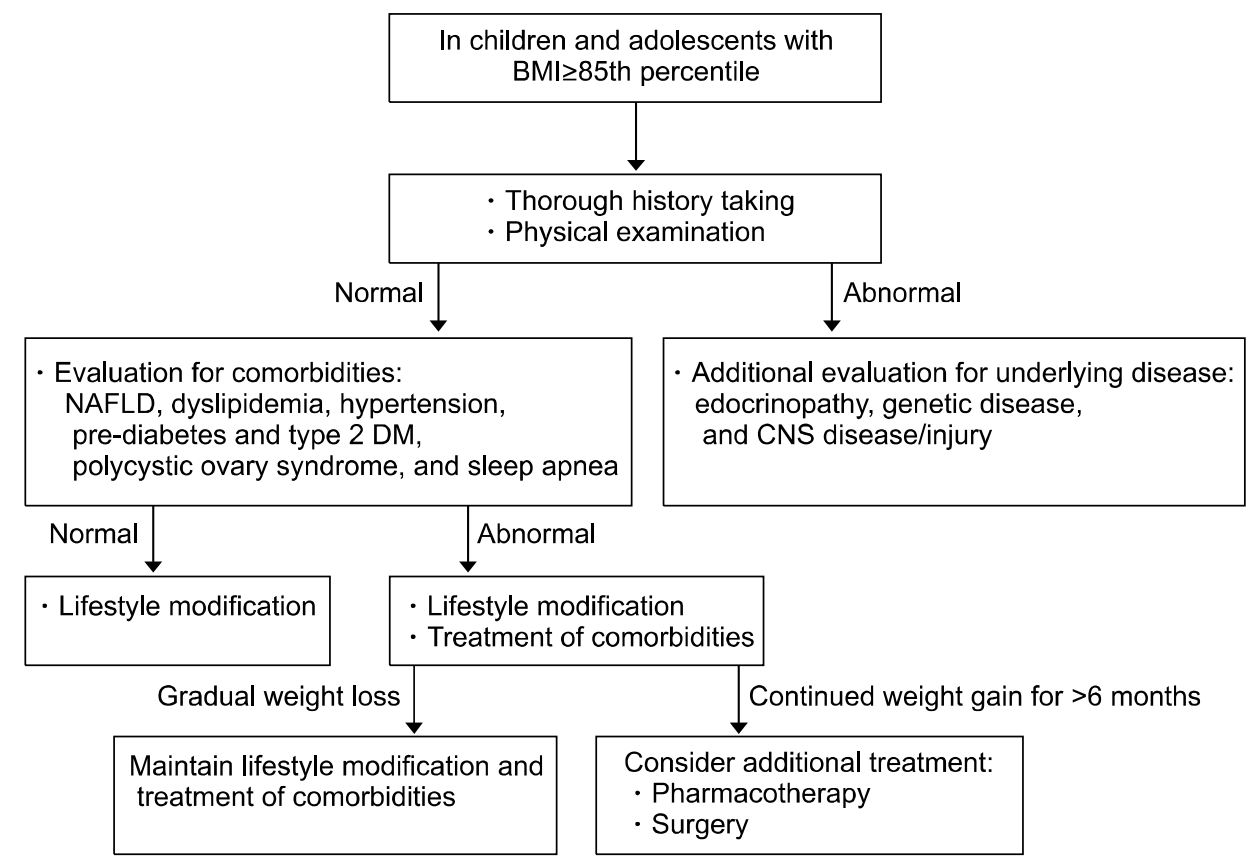

Fig. 1. Stepwise assessment and treatment strategies for overweight and obesity children and adolescents. BMI: body mass index, NAFLD: nonalcoholic fatty liver disease, DM: diabetes mellitus, CNS: central nervous system. 
Table 2. Lists of Obesity-Related Comorbidity and Corresponding Screening Tests

\begin{tabular}{|c|c|}
\hline Comorbidity & Definitions \\
\hline NAFLD & $\begin{array}{l}\text { Alanine aminotransferase; } \geq 26 \mathrm{U} / \mathrm{L} \text { (boys) and } \geq 22 \mathrm{U} / \mathrm{L} \text { (girls) } \\
\text { Ultrasonography, if indicated }\end{array}$ \\
\hline Prediabetes & $\begin{array}{l}\text { HbAlc of } 5.7 \% \text { to } 6.5 \% \text { ( } 39 \text { to } 48 \mathrm{mmol} / \mathrm{mol}) \\
\text { Fasting plasma glucose; } 100 \text { to } 125 \mathrm{mg} / \mathrm{dL}(5.5 \text { to } 6.9 \mathrm{mmol} / \mathrm{L}) \\
\text { Two-hour plasma glucose; } 140 \text { to } 199 \mathrm{mg} / \mathrm{dL}(7.8 \text { to } 11.0 \mathrm{mmol} / \mathrm{L})\end{array}$ \\
\hline Type 2 DM & $\begin{array}{l}\text { HbAlc } \geq 6.5 \% \text { ( } \geq 48 \mathrm{mmol} / \mathrm{mol}) \\
\text { Fasting plasma glucose; } \geq 126 \mathrm{mg} / \mathrm{dL}(\geq 7.0 \mathrm{mmol} / \mathrm{L}) \\
\text { Two-hour plasma glucose; } \geq 200 \mathrm{mg} / \mathrm{dL}(\geq 11.1 \mathrm{mmol} / \mathrm{L}) \text { during an oral glucose tolerance test } \\
\text { In a patient with classic symptoms of hyperglycemia, a random plasma glucose; } \geq 200 \mathrm{mg} / \mathrm{dL}\end{array}$ \\
\hline Dyslipidemia & $\begin{array}{l}\text { Fasting triglycerides (mg/dL) (multiply by } 0.0113 \text { to convert to mmol/L): } \\
0-9 \mathrm{y} ;<75 \text { (acceptable), } 75-99 \text { (borderline high), } \geq 100 \text { (high) } \\
\text { 10-19 y; }<90 \text { (acceptable), } 90-129 \text { (borderline high), } \geq 130 \text { (high) } \\
\text { LDL cholesterol (mg/dL) (multiply by } 0.0259 \text { to convert to mmol/L): } \\
\quad<110 \text { (acceptable), } 110-129 \text { (borderline high), } \geq 130 \text { (high) } \\
\text { Total cholesterol (mg/dL) (multiply by } 0.0259 \text { to convert to mmol/L): } \\
\quad<170 \text { (acceptable), 170-199 (borderline high), } \geq 200 \text { (high) } \\
\text { HDL cholesterol (mg/dL) (multiply by } 0.0259 \text { to convert to mmol/L): } \\
\quad<40 \text { (low), 40-45 (borderline low), }>45 \text { (acceptable) } \\
\text { Non-HDL cholesterol (mg/dL) (multiply by } 0.0259 \text { to convert to mmol/L) (can be nonfasting) } \\
\quad<120 \text { (acceptable), 120-144 (borderline high), } \geq 145 \text { (high) }\end{array}$ \\
\hline $\begin{array}{l}\text { Prehypertension } \\
\text { and hypertension }\end{array}$ & $\begin{array}{l}\text { 3-11 y: (standardized according to sex, age, and height percentile) } \\
\text { BP of }>90 \text { th percentile to }<95 \text { th percentile }=\text { prehypertension } \\
\text { BP of } \geq 95 \text { th percentile to }<99 \text { th percentile }+5 \mathrm{mmHg}=\text { stage } 1 \mathrm{HTN} \\
\text { BP of } \geq 99 \text { th percentile }+5 \mathrm{mmHg}=\text { stage } 2 \mathrm{HTN} \\
12-17 \text { y: (standardized according to sex, age, and height percentile) } \\
\text { BP of }>90 \text { th percentile to }<95 \text { th percentile or }>120 / 80 \mathrm{mmHg}=\text { prehypertension } \\
\text { BP of } \geq 95 \text { th percentile to }<99 \text { th percentile }+5 \mathrm{mmHg}=\text { stage } 1 \mathrm{HTN} \\
\text { BP of } \geq 99 \text { th percentile }+5 \mathrm{mmHg}=\text { stage } 2 \mathrm{HTN}\end{array}$ \\
\hline PCOS & $\begin{array}{l}\text { Free and total testosterone and sex hormone binding protein } \\
\text { Ultrasonography, if indicated }\end{array}$ \\
\hline Obstructive sleep apnea & $\begin{array}{l}\text { If there is a positive history, refer to a pulmonologist for nocturnal polysomnography and, if not } \\
\text { available, overnight oximetry }\end{array}$ \\
\hline Psychiatric problem & If there is a positive history, refer to a mental health specialist. \\
\hline
\end{tabular}

NAFLD: non-alcoholic fatty liver disease, DM: diabetes mellitus, HbAlc: hemoglobin Alc, LDL: low density lipoprotein, HDL: high density lipoprotein, BP: blood pressure, HTN: hypertension, PCOS: polycystic ovary syndrome.

\section{Principles of the treatment of pediatric obesity}

2-1. We recommend a treatment algorithm to help physicians determine the appropriate weight management stage for each patient, on the basis of his or her age, BMI percentile, and comorbidities. (Strength of evidence, I; grade of recommendation, A)

2-2. We recommend a family-based, comprehensive, multidisciplinary team approach to succeed in behavioral interventions (active vigorous physical activity and reduction of inactivity, accompanied with calorie-controlled diet) for the treat- ment of obesity in children. (Strength of evidence, I; grade of recommendation, A)

2-3. We recommend that pharmacotherapy and bariatric surgery be considered only in patients with morbid obesity with major comorbidities after a formal program of intensive lifestyle modification has failed. (Strength of evidence, V; grade of recommendation, A, based on committee voting) 
2-1. Treatment algorithm to help physicians determine the appropriate weight management stage for each patient, on the basis of his or her age, BMI percentile, and comorbidities (Strength of evidence, l; grade of recommendation, A)

Behavioral interventions for lifestyle modification represent the key principle recommended for the treatment of overweight and obesity in children and adolescents. The following are the staged treatment strategies for pediatric obesity according to age and BMI percentile [23]:

1) Children aged 2 to 5 years

(1) BMI 85th-94th percentile (overweight) The weight goal is weight maintenance until reaching a BMI below the 85th percentile or slowing of weight gain, as indicated by the downward deflection in the BMI curve.

(2) BMI 95th-98th percentile (obesity) The weight goal is weight maintenance until reaching a BMI below the 85th percentile; however, if weight loss occurs with healthy, adequate-energy diet, it should not exceed $0.5 \mathrm{~kg} / \mathrm{month}$. If greater weight loss is noted, monitor the patient for causes of excessive weight loss.

(3) BMI $\geq 99$ th percentile (severe obesity)

The weight goal is gradual weight loss not exceeding $0.5 \mathrm{~kg} / \mathrm{month}$. If greater weight loss occurs, monitor the patient for causes of excessive weight loss.

2) Children aged 6-11 years

(1) BMI 85th-94th percentile (overweight) The weight goal is weight maintenance until reaching a BMI not exceeding the 85th percentile or slowing of weight gain, as indicated by the downward deflection in the BMI curve.

(2) BMI 95th-98th percentile (obesity)

The weight goal is weight maintenance until reaching a BMI of below the 85th percentile or gradual weight loss of approximately 0.5 $\mathrm{kg} /$ month. If greater loss is noted, monitor the patient for causes of excessive weight loss.

(3) BMI $\geq 99$ th percentile (severe obesity)

The weight goal is weight loss not exceeding the average of $0.9 \mathrm{~kg} /$ week. If greater weight loss is noted, monitor the patient for causes of excessive weight loss.

3) Adolescents aged 12-18 years

(1) BMI 85th-94th percentile (overweight)

The weight goal is weight maintenance until reaching a BMI not exceeding the 85th percentile or slowing of weight gain, as indicated by the downward deflection in the BMI curve.

(2) BMI 95th-98th percentile (obesity)

The weight goal is weight loss until reaching a BMI below the 85th percentile, with no more than an average of $0.9 \mathrm{~kg} / \mathrm{week}$. If greater weight loss is noted, monitor the patient for causes of excessive weight loss.

(3) BMI $\geq 99$ th percentile (severe obesity)

The weight goal is weight loss not exceeding the average of $0.9 \mathrm{~kg} /$ week. If greater weight loss is noted, monitor the patient for causes of excessive weight loss. Patients may warrant tertiary care evaluation to determine the next level of treatment.

2-2. We recommend a family-based, comprehensive, multidisciplinary team approach to succeed in behavioral interventions (active vigorous physical activity and reduction of inactivity, accompanied with calorie-controlled diet) for the treatment of obesity in children. (Strength of evidence, I; grade of recommendation, A)

The interactions between parents and children and parenting styles strongly affect the unhealthy lifestyle habits of children [24]. Obese children are more likely to be bullied and have fewer friends or are less popular among classmates compared with thinner peers [25]. Parents, teachers, and friends have indicated that youths who are obese are easily isolated and have poorer social relationships compared with their counterparts [26]. Those with low self-esteem and higher BMIs are more likely to smoke and drink alcohol [27]. These children are also less athletic and are not expected to have romantic relationships. Thus, they tend to demonstrate teasing, worsening of self-esteem, feeling of loneliness, 
depression, anxiety, and an introverted personality [28].

Data from 133 RCTs enrolling 30,445 patients through 16 systemic reviews presented an evidence profile for each intervention, including medication, surgery, and lifestyle or community-based interventions, in overweight or obese children or adolescents. Physical activity interventions decrease systolic blood pressure (BP) and fasting glucose (low to moderate quality of evidence). Dietary interventions with low-carbohydrate diets have shown an effect in terms of BMI reduction (moderate quality of evidence). Educational interventions reduce waist circumference, BMI, and diastolic BP (low quality of evidence). Pharmacological interventions reduce BMI (metformin, sibutramine, and orlistat) and waist circumference (sibutramine and orlistat) as well as increase high-density lipoprotein cholesterol (sibutramine) but also raise systolic and diastolic BP (sibutramine). Surgical interventions (laparoscopic adjustable gastric banding, Roux-en-Y gastric bypass, and sleeve gastrectomy) have shown the largest BMI reduction (moderate quality of evidence). Combined interventions consisting of dietary modification, physical activity, behavioral therapy, and education significantly reduce systolic and diastolic BP, BMI, and triglycerides. Combined parent-child and parent-only interventions have similar effects on BMI (low quality of evidence) [29].

A school-based intervention reportedly reduces BP and body fat in young teenagers. Short-term cardiovascular health in children-targeted interventions showed successful results in demonstrating affected physiological variables according to increased time spent in moderate to vigorous physical activity at school (20 minutes per day in elementary schools, 30 minutes in middle schools) [30]. Both school-designed workout and adult supervision in physical activities affected the amount of physical activity of sixth to eighth graders participating in their free time [31].

A systemic analysis of 24 reports reviewing 15 studies showed strong evidence that reduced screen time and enhanced physical activity could prevent obesity. Data from 11,000 preschool children 4 to 6 years of age linked increased caloric intake from snacks and sugar-sweetened beverages with increased screen time [32]. Another study revealed that decreasing screen time also decreases sedentary time [33]. A two-generation study associated increased BMI with two hours of screen time per day for both parents and offspring [34].

In a prospective cohort study in England of a family-based behavioral treatment in 33 families with severely obese children aged 8 to 13 years, the families were advised to practice self-monitoring, keeping daily food and activity records, goal setting, positive reinforcement, and stimulus control to modify the child's eating and exercise behaviors. Foods were categorized into "traffic light" food colors of red, yellow, and green foods; physical activity aspects were also advised. Severely obese children were reported to have lost $8.4 \%$ of BMI over three months, maintained at the three-month follow-up. Self-esteem and depression also improved significantly [35].

A study concerning the relationship between parenting style and development of obesity in children showed that authoritarian parenting is highly associated with the risk of being overweight among young children [24].

Interviews performed in children with obesity and parents with obese children revealed that a lifestyle behavior improvement program benefits from parental support and needs help from family, peers, and friends [36]. The studied children with obesity benefited from the persistent involvement of supportive persons in the maintenance of lifestyle behavior changes. The respondents expected to achieve weight reduction by physical activity or eating healthy meals. The parents reported struggling with adopting new rules and insufficient support from family members. Children reported suffering from inconsistent parenting and low support from their parents. Their experience of bullying at school was an obstacle to their ability to achieve the necessary changes. Support from peers stimulated their progress. Parents identified that the general practitioner is required to discuss overweight in a non-offensive 
manner and to present interest in the process of weight reduction. The general practitioner should play a more supportive role [36].

The Oklahoma Chapter of the American Academy of Pediatrics Obesity Committee developed a resource toolkit for pediatric primary care providers to be used in behavioral counseling of obese children. Eight topics were selected for the handouts: sugars-sweetened beverages, daily screen time, sleep, proper breakfast, family mealtime, physical activity, balanced meals, and food quality. The resource toolkit sets four steps, utilizing motivational interviewing techniques, to assist with facilitating behavior change: 1) obtaining patient history, 2) discussing health habits and the family's reasons for changing habits, 3) setting a realistic goal for change, and 4) realizing goals. This handout also provides a patient questionnaire on health habits to assist with the identification of behaviors to be changed, eight provider and parent handouts on healthy behaviors, and a motivational interviewing guide [37].

Behavioral interventions target lifestyle change (e.g., counseling on diet, increasing physical activity or decreasing sedentary behavior, and addressing behavior change) to limit weight gain or decrease weight [38]. Effective behavioral interventions include parental support and the delivery of basic instructive information on healthy nutrition and physical activity. Additional components of the most effective interventions include the following: 1) being conducted in a specialty setting; 2 ) targeting both children and their parents; 3 ) helping parents and children engage in stimulus control (e.g., limiting access to tempting foods and limiting screen time); and 4) assisting participants in identifying goals, self-monitoring, and problem solving to accomplish their selected goals. Other common components include contingent use of rewards or reinforcement, motivational interviewing, teaching of coping skills, addressing body image, and the option of individualfamily counseling to address family-specific issues. All of the effective studies have emphasized eating healthy foods and using moderate portions.

The distinguishing characteristics of compre- hensive multidisciplinary interventions are increased intensity of behavioral change strategies, greater frequency of patient-provider contact, and involvement of specialists in the treatment. Formalized behavioral therapy and a multidisciplinary treatment team exceed the capacity of the services most primary care providers can supply.

Systematic evaluation of body measurements, dietary intake, and physical activity should be conducted at baseline and at specific intervals throughout a program. For the implementation of a comprehensive multidisciplinary intervention, the comprehensive treatment should be provided by a multidisciplinary obesity care team, including a behavioral counselor (for example, social worker, psychologist, other mental health care provider, or trained nurse practitioner), registered dietitian, and exercise specialist (physical activity specialist or another team member with training or a community program prepared to assist children with obesity).

2-3. We recommend that pharmacotherapy and bariatric surgery be considered only in patients with morbid obesity with major comorbidities after a formal program of intensive lifestyle modification has failed. (Strength of evidence, $V_{\text {; }}$ grade of recommendation, $A$, based on committee voting)

Pharmacotherapy should only be performed in accordance with lifestyle modification [39]. The prescription of weight-reducing medicines used off-label to adolescents under 16 years of age should be discouraged for the following reasons: 1) the lack of Food and Drug Administration (FDA) approval, 2) insufficient number of safety and efficacy studies performed in children and adolescents with obesity, 3) limited efficacy for most agents, and 4) the problem of drug-induced adverse reaction related with potential obesity-related morbidity and mortality. For obese youth who are unable to achieve sufficient weight loss with lifestyle interventions alone, adjunctive use of more intensive treatments, including pharmacotherapy, may be appropriate. However, the search for obesity medications that are proved to be safe for long-term use, efficacious to promote sufficient weight 
reduction, and have a good risk-benefit ratio remains fruitless. Nevertheless, there is great hope in the successful development of more effective, etiology-based anti-obesity therapies for children and adults.

FDA-approved pharmacotherapy for obesity should be administered only with a concomitant lifestyle modification program of the highest intensity available, and only by clinicians who are experienced in the use of anti-obesity agents and aware of their risk for adverse reactions [40]. Medication should be discontinued, and the patient re-evaluated, if the reduction in BMI or BMI $z$ score is less than $4 \%$ after anti-obesity medication for 12 weeks at full dosage [11].

In adolescents with extreme obesity, clinicians may consider bariatric procedures if the patient shows poor response to medical treatment for weight loss. Indications for bariatric surgery include BMI of $>35 \mathrm{~kg} / \mathrm{m}^{2}$, accompanying comorbidities of obesity such as type $2 \mathrm{DM}$, moderate-to-extreme sleep apnea, pseudotumor cerebri, debilitating orthopedic problems, and non-alcoholic steatohepatitis with advanced fibrosis. Another candidate profile for bariatric surgery is a BMI of $>40 \mathrm{~kg} / \mathrm{m}^{2}$ with mild comorbidities (hypertension, dyslipidemia, moderate orthopedic problems, mild sleep apnea, non-alcoholic steatohepatitis, and extreme psychological distress that is secondary to the obesity) $[41,42]$.

\section{Behavioral intervention for children and adolescents with obesity: Diet}

3-1. We recommend the decrease in intake of sugar-sweetened beverages. (Strength of evidence, I; grade of recommendation, A)

3-2. We recommend the reduction in total energy intake. (Strength of evidence, I; grade of recommendation, A)

3-3. We suggest the use of small-sized plates or bowls. (Strength of evidence, III; grade of recommendation, $\mathrm{C}$ )

3-4. We suggest the decrease in consumption of fast food. (Strength of evidence, III; grade of recommendation, C)
3-1. We recommend the decrease in intake of sugar-sweetened beverages. (Strength of evidence, l; grade of recommendation, A)

The Korean National Health and Nutrition Examination Survey performed between 2008 and 2011 revealed that the mean amount of daily sugar-sweetened beverage consumption was 98.7 $\mathrm{mL} /$ day in school children, which tended to increase with age [43]. This Korean study revealed that overweight and obesity are significantly associated with high sugar-sweetened beverage intake among boys aged 7 to 12 years (odds ratio, 1.72) [43]. A randomized trial performed in adolescents aged 13 to 18 years demonstrated that BMI changes are significant between a sugar-sweetened beverage restricted group and a control group among subjects in the upper-baseline BMI percentile [44]. A more recent randomized trial that investigated the effects of an intervention designed to decrease consumption of sugar-sweetened beverages on weight gain showed significant differences in the BMI changes between the intervention group and control group at both one and two years among Hispanic adolescents [45]. Similar to the results from studies in older children, sugar-sweetened beverage consumption has been positively associated with BMI z scores in children at four and five years in a large-scale, longitudinal cohort study [46]. A recent systematic review revealed a significant positive association between sugar-sweetened beverage consumption and total adiposity among children under 12 years old [47]. A cross-sectional analysis of children's dietary data reported that sugar-sweetened beverage intake is independently associated with alterations in lipid profiles, increased markers of inflammation, and increased waist circumference [48].

3-2. We recommend the reduction in total energy intake. (Strength of evidence, l; grade of recommendation, A)

Current evidence suggests that weight status can be improved in overweight or obese children and adolescents by a reduced-energy diet. However, the association between weight improvement and mac- 
ronutrient distribution of a reduced-energy diet is controversial in children and adolescents [49].

In an adult systemic review, the overweight and obese population who consumed low glycemic index food lost more weight and showed better improvement in lipid profiles [50]. A pediatric systematic review comparing low glycemic index/low glycemic load with high glycemic index/high glycemic load diets did not reveal the effect of weight loss; however, it reported decreases in serum triglyceride and Homeostasis Model Assessment (HOMA) index [51].

Meanwhile, studies on the association between eating quickly and overweight/obesity have showed conflicting results. Several cohort studies conducted in Japan have demonstrated that eating quickly is significantly associated with overweight in girls [52,53]. A population-based study conducted in Portugal reported no significant association between eating quickly and overweight/obesity [54].

There is weak evidence regarding the association between breakfast intake and obesity [55-58]. Likewise, current evidence does not show that the consumption of fruits and vegetable is associated with overweight and obesity in children and adolescents $[59,60]$. In an adult study, energy density independently affects energy intake; however, data are lacking for children and adolescents [61].

3-3. We suggest the use of small-sized plates or bowls. (Strength of evidence, III; grade of recommendation, C)

Systematic reviews in adults have consistently shown that energy intake increases with larger portion sizes [61]. A recent systematic review showed that children also consistently consume more food and drink when offered larger-sized portions, packages, or tableware than when offered smaller-sized versions [62]. Total calorie consumption reportedly decreases in those receiving small portion sizes among children under six years of age [63,64]. A recent observational study revealed that reduced portion sizes are associated with BMI reduction after one and two years among children and adolescents [65].
3-4. We suggest the decrease in consumption of fast food. (Strength of evidence, III; grade of recommendation, C)

The intake of fast food has an effect on overweight and obesity in school children and adolescents. Composition data from leading fast food company websites show that fast foods have very high energy density $[66,67]$. A Korean nationwide observational study performed in 2001 reported contrasting results regarding the association between fast food intake and overweight and obesity [68]. However, a recent large-scale observational study performed in Jeju Island revealed that obese children had significantly higher rates of fast food consumption [69].

\section{Behavioral intervention for children and adolescents with obesity: Exercise}

4-1. We recommend physical activity, which is beneficial to all children and adolescents. (Strength of evidence, I; grade of recommendation, A)

4-2. We recommend moderate to vigorous levels of physical activity, including regular and steady exercise, which is helpful in promoting a decrease in weight. The recommended duration of moderate tovigorous exercise is at least 20 minutes, with a goal of 60 minutes, five days per week. (Strength of evidence, I; grade of recommendation, A)

4-3. We recommend programmed exercises, which are helpful in reducing body fat in children and adolescents. (Strength of evidence, I; grade of recommendation, A)

4-1. Physical activity is beneficial to all children and adolescents. (Strength of evidence, l; grade of recommendation, A)

Physical activity is especially effective in enhancing cardiovascular fitness, decreasing body fat, and lowering risk factors for diabetes [70-73]. Apart from the benefits for maintaining weight and reducing health risks related to childhood obesity, physical ac- 
tivity may prove to enhance aspects of children's brain activation, including cognitive development $[74,75]$. Therefore, the WHO, American Alliance for Health, Physical Education, Recreation and Dance, British Association of Sport and Exercise Medicine, and Canadian Academy of Sport and Exercise Medicine recommend for children to participate in physical activities as early as possible. Guidelines that recommend suitable physical activities for each age group have also been formulated in developed countries.

1) Children and youth aged 5 tol 7 years should accumulate at least 60 minutes of moderate- to vigorous-intensity physical activity daily.

2) Physical activity greater than 60 minutes in duration provide more health benefits.

3) Most of the daily physical activity should be aerobic. Vigorous-intensity activities should be incorporated, including those that strengthen muscle and bone, and performed at least three times per week.

4-2. Moderate to vigorous levels of physical activity, including regular and steady exercise, are helpful in promoting a decrease in weight. (Strength of evidence, I; grade of recommendation, A)

Regular exercises improve weight and BMI, as well as blood sugar and triglyceride levels [70, 76-78]. The degree of weight loss is maximized when exercise is combined with decreased calorie intake, which is also helpful in sustaining improved weight after weight loss. The degree of weight loss is minimal in the absence of calorie intake restriction.

Moderate exercise refers to exercise that causes mild increases in breathing and heart rate $[71,74]$. In other words, conversation is doable during moderate exercise, whereas singing is difficult to perform simultaneously. Brisk walking, cycling, and practice

Table 3. Stepwise Exercise Strategies according to Age and Obesity Status

\begin{tabular}{|c|c|c|c|}
\hline Age group & Obesity status & First intervention step & Advanced intervention step \\
\hline Infant $(<2$ y) & Weight for height $\geq 95$ th percentile & Prevention counselling & Prevention counselling \\
\hline \multirow[t]{3}{*}{$\begin{array}{l}\text { Early childhood } \\
(2-5 \text { y })\end{array}$} & $\begin{array}{l}\text { BMI 5th-84th percentile } \\
\text { BMI 85th-94th percentile with no risks }\end{array}$ & Prevention counselling & Prevention counselling \\
\hline & BMI 85th-94th percentile with risks & Step 1 & Step 2 \\
\hline & BMI $\geq 95$ th percentile & Step 1 & Step 3 \\
\hline \multirow[t]{4}{*}{$\begin{array}{l}\text { Middle childhood } \\
(6-11 \text { y) }\end{array}$} & $\begin{array}{l}\text { BMI 5th-84th percentile } \\
\text { BMI 85th-94th percentile with no risks }\end{array}$ & Prevention counselling & Prevention counselling \\
\hline & BMI 85th-94th percentile with risks & Step 1 & Step 2 \\
\hline & BMI 95th-99th percentile & Step 1 & Step 3 \\
\hline & BMI >99th percentile & $\begin{array}{l}\text { Step } 1 \\
\text { Step } 2 \text { or } 3 \text {, if family is motivated }\end{array}$ & Step 4 , if appropriate \\
\hline \multirow[t]{4}{*}{$\begin{array}{l}\text { Adolescence } \\
(12-18 \text { y) }\end{array}$} & $\begin{array}{l}\text { BMI 5th-84th percentile } \\
\text { BMI 85th-94th percentile with no risks }\end{array}$ & Prevention counselling & Prevention counselling \\
\hline & BMI 85th-94th percentile with risks & Step 1 & Step 2 \\
\hline & BMI 95th-99th percentile & Step 1 & \\
\hline & BMI >99th percentile & $\begin{array}{l}\text { Step } 1 \\
\text { Step } 2 \text { or } 3 \text { if patient and } \\
\text { family are motivated }\end{array}$ & Step 4, if appropriate \\
\hline
\end{tabular}

Step 1: Prevention plus management; Be physically active $\geq 1$ hour each day. Young children: unstructured play in young children. Older children: should find physical activities that they enjoy.

Step 2: Structured weight management; Planned, supervised, physical activity or active play for 60 minutes per day.

Step 3: Comprehensive multidisciplinary management; Physical activity goal setting, and contingency management. Negative energy balance resulting from structured physical activity changes is planned. Multidisciplinary team with experience in childhood obesity including exercise specialist.

Step 4: Tertiary care management. BMI: body mass index. 
in such sports as soccer, basketball, and badminton, are examples of moderate exercise. Meanwhile, conversation is difficult and singing impossible during vigorous exercise, owing to significant increases in breathing and heart rate. Running fast, jump rope workout, inline skating, and playing a game of soccer, basketball, or badminton are examples of vigorous exercise. At least 20 minutes of moderate exercise is recommended, with a goal of 60 minutes, five days per week, whereas vigorous exercise is effective when done three times per week $[75,79,80]$.

4-3. Programmed exercises are helpful in reducing body fat in children and adolescents. (Strength of evidence, l; grade of recommendation, A)

The effect of exercise programs is maximized with the involvement of a specialist to instruct the activity or when friends or family members participate in together [81-83]. The type, frequency, intensity, and duration of exercises should be included in the prescription of the program. Moreover, prescriptions for resistance training programs should be individualized to stimulate all of the major muscle groups and use all of the muscle groups [72].

In addition, exercise intensity should be adjusted stepwise according to age and BMI, rather than engaging in high-level exercise from the beginning [14]. Especially in patients with high-level obesity, weight-bearing exercise, such as excessive jump rope, should be avoided because repeated impact may be applied to parts such as knees, ankles, and hip joints (Table 3). However, according to a recent meta-analysis that investigated the impact of physical education on obesity prevention in children, adolescents, and adults, although physical education has positive effects on obesity-related body indices and health status, its effect is statistically insignificant. Moreover, there is lack of evidence based on data [72].

\section{Behavioral intervention for children and adolescents with obesity: Lifestyle}

5-1. We recommend increasing physical activity and limiting sedentary time (non-academic screen time, digital activities) to one to two hours per day for weight reduction. (Strength of evidence, I; grade of recommendation, $\mathrm{A}$ )

5-2. We recommend maintaining adequate sleep duration for the prevention of obesity in children and adolescents. (Strength of evidence, I; grade of recommendation, A)

5-3. We recommend a family-centered approach, including parents, to prevent and treat children's obesity effectively; parental obesogenic lifestyle habits are related to children's obesity. (Strength of evidence, I; grade of recommendation, A)

5-4. We recommend the development of specific public health interventions as essential to overweight and obesity control in children with lower socioeconomic status (SES). ( Strength of evidence, I; grade of recommendation, A)

5-5. We recommend that obesity interventions be conducted in multiple key childhood environments, including family, school, and community. (Strength of evidence, I; grade of recommendation, A)

5-1. We recommend increasing physical activity and limiting sedentary time (non-academic screen time, digital activities) to one to two hours per day for weight reduction. (Strength of evidence, l; grade of recommendation, A)

Obese children tend to commute to school by school bus rather than walk to school [84-86]. The sedentariness of obese children is higher than that in normally weighted children; the former have been shown to like to lie down when staying indoors and use the elevators more than stairs $[84,87,88]$. Obese children spend a high proportion of their day watching television or using the personal computer compared with normally weighted children [84,89-91]. Increased television-viewing time decreases physical activity, and can increase the consumption of 
high-calorie diet through being exposed to television commercials of high-calorie foods, such as fast food, snack, and soft drinks [84,92-96]. The effort to walk as much as possible and exercise regularly is significantly related to losing body weight [86].

5-2. We recommend maintaining adequate sleep duration for the prevention of obesity in children and adolescents. (Strength of evidence, l; grade of recommendation, $\mathrm{A}$ )

A school-based, cross-sectional study of 3,785 Korean adolescents in middle and high school between the ages of 11 and 18 years showed the significant association of longer sleep duration on both week day and weekends with decreased BMI for both sexes [97]. A study using data of 489 adolescents aged 12 to 18 years from the Korean National Health and Nutrition Examination Survey from 2013 to 2014 showed that the risk of obesity decreases with increased sleep duration [98]. Researches in Canada, Japan, and China showed an inverse correlation between sleep duration and obesity in children [98-101].

Sleep restriction results in significant increases in caloric intake $[102,103]$. Short sleep is associated with decreased moderate to vigorous physical activity and increased sedentary time [102,104]. A significant negative association has been observed between sleep duration and screen time [102,105]. Short sleep is also associated with insulin resistance [102].

5-3. We recommend a family-centered approach, including parents, to prevent and treat children's obesity effectively; parental obesogenic lifestyle habits are related to children's obesity. (Strength of evidence, l; grade of recommendation, A)

According to a meta-analysis conducted with studies published between 2000 and 2009, the majority of studies $(70 \%)$ have shown statistically significant moderate to large effect size changes in child BMI after participation in a family-based intervention for weight loss. Of these, 50\% reported statistically significant weight loss changes at six- month, one-year, and two-year follow-up, albeit with small to moderate effect sizes [106].

In a study of Korean first-grade elementary school students and their parents, parental lifestyle habits were shown to induce children's obesity [107]. Children of obese parents are more likely to be diagnosed as overweight compared with children of normal-weight parents. Among the paternal lifestyle habits, hours of watching television or computer usage, and consumption frequency of soda, ice cream, cake, and chips are related to the children being overweight. Among the maternal lifestyle habits, hours of watching television or computer usage, frequency of eating breakfast, and frequency of overeating are related to the children being overweight. Parents' lifestyle habits can affect children's weight via an effect on the children's lifestyle habits. The degree of obesity between parents and children tends to be similar because parents and children share not only genes but also the same family environment. Family environment plays an important role in forming children's lifestyle, including eating habits and physical activity through parents' lifestyles. As the mother tends to take the main role in rearing children, maternal obesogenic lifestyles have greater influence on children's obesity.

5-4. We recommend the development of specific public health interventions as essential for overweight and obesity control in children with lower SES. (Strength of evidence, I; grade of recommendation, A)

According to a study based on data of the Korea National Health and Nutrition Examination Survey 2007-2010 conducted by the Korea Centers for Disease Control and Prevention, SES does not affect the observed relationships of overweight or obesity in children aged 2 to 18 years [108]. However, recent published systematic reviews and meta-analyses have showed that children with lower SES have higher risks of being diagnosed with overweight and obesity [109,110]. Another systematic review and meta-analysis of studies published between 1990 and 2014 showed that low SES is associated with a 
$10 \%$ higher risk of overweight and a $41 \%$ higher risk of obesity in children aged 0 to 15 years [109]. In a subgroup analysis, this relationship was prominent in high-income countries and in more economic developed areas, including North America, Europe, and Oceania [109]. Another systematic review to describe the relationship between SES and childhood/adolescent weight status in papers published in rich countries from 1990 through 2013 showed a predominantly inverse relationship [110].

Adolescents from areas with low SES more often skipped breakfast and more often ate snacks compared with adolescents from high SES areas [111,112]. SES has been positively associated with food frequency intake scores in both sexes. Adolescents with low SES tended to show an irregular meal pattern [31,33]. High household SES is also associated with increased intakes of vegetables, fruits, and dietary fiber, and with decreased intakes of fat $[111,113,114]$.

A study on the association among parental socioeconomic level, overweight, and eating habits with diet quality in Korean sixth-grade school children showed that a lower SES (in terms of parental income or parental education level) relates to the consumption of significantly fewer fruits [111]. In the same study, the children in the lower socioeconomic group had a lower food habit score (high frequency of breakfast skipping and ramen noodle consumption), diet quality, and intake of nutrients compared with those in the higher socioeconomic group. Lower maternal education status is also associated with a higher risk for being overweight in girls. Specific public health interventions should support parents and children with lower SES to develop health-related behaviors that may prevent childhood obesity.

5-5. We recommend that obesity interventions be conducted in multiple key childhood environments, including the family, school, and community. (Strength of evidence, I; grade of recommendation, A)

Most strategies for preventing or reducing childhood obesity have focused on individual behavior modification with limited success $[115,116]$. The environment of children with obesity, including family, schools, after-school programs, and community, as well as the policy level, can be changed to promote healthier lifestyles through multi-level obesity interventions $[115,117]$. The family represents the closest environment of children; thus, the family is important to forming the healthy lifestyle of children $[115,107]$. School is the place where students spend most of their time beginning with the time they reach schooling age $[115,118]$. Children can maintain and manage a healthy lifestyle through teacherpupil interaction and peer interaction $[115,118]$. In the treatment or prevention of childhood obesity, a variety of support systems through parents, peers, and teacher relationships can induce changes in the overall environment surrounding children, thereby raising the effectiveness of any obesity intervention [115]. Multidisciplinary interventions can make obese children continue a healthy lifestyle [115]. Obesity in children and adolescents is linked to adult obesity and various diseases, leading to an increase in public medical expenses. Therefore, national policy is needed in leading efforts to preventing obesity fundamentally and to establishing education and policy for health promotion.

\section{Behavioral intervention for children and adolescents with obesity: Mental health}

6-1. We recommend that obese children be monitored for psychological problems and screened for the need for psychiatric treatment. (Strength of evidence, I; grade of recommendation, A).

6-2. We recommend that physicians emphasize family functioning and let the family participate in the treatment of the obese child. (Strength of evidence, I; grade of recommendation, A).

6-3. We recommend cognitive behavioral therapy, which may be beneficial to treating child obesity. (Strength of evidence, III; grade of recommendation, $\mathrm{C}$ ) 
6-1. We recommend that obese children be monitored for psychological problems and screened for the need for psychiatric treatment. (Strength of evidence, l; grade of recommendation, A)

Obese children may be suffering from low self-esteem, body shape dissatisfaction, depression, eating disorder, obesity stigma, teasing, or bullying by peers [119-125]. They also live with significantly lower health-related quality of life compared with normal weighing children, or several pediatric chronic diseases [126]. Obese children complain of a low quality of life associated with physical and psychosocial health, and emotional, social, and school functioning [126,127].

Extremely obese adolescents have higher rates of mood, anxiety, somatoform, and eating disorders compared with a population-based control group [128]. The screening tools for psychological problems include the Korean-Child Behavior Checklist, Children's Depression Inventory, Korean version of the Eating Attitude Test-26, somatotype drawings, and Pediatric Quality of Life Inventory [121-123,126,127].

6-2. We recommend that physicians emphasize family functioning and let the family participate in the treatment of the obese child. (Strength of evidence, l; grade of recommendation, A)

Poor family functioning is associated with increased risk of obesity and overweight $[129,130]$. The elements of poor family functioning related to obesity are poor communication, poor behavior control, high levels of family conflict, and low family hierarchy values [130]. Although standardized family functioning measures are necessary, half of the identified intervention studies reported a significant relationship between family functioning and changes in child weight [130]. Contrary to these reports, several studies have reported that family functioning is not associated with child obesity; rather, an overweight mother is largely linked to child obesity $[131,132]$. Given the high correlation of parental or mother's obesity with child obesity, parental behavior changes in the family should be considered $[132,133]$. Family-based treatment is crucial to con- trol nip successfully child obesity.

6-3. We suggest cognitive behavioral therapy, which might be beneficial to treating child obesity. (Strength of evidence, III; grade of recommendation, C)

Cognitive behavioral therapy (CBT) is effective in treating childhood obesity [134-136]. The treatment goal is weight control by healthy changes in lifestyle rather than weight reduction. The key element of this therapy is self-regulation, with techniques including learning self-instructions (e.g., "stop and think"), self-observation, self-evaluation, and selfreward [136]. To train self-regulation skills, modeling (showing the coping skills to the child), behavior rehearsal, and homework have been used [136]. Coping skills are taught for different stressful situations (e.g., feeling alone) and relapse moments (e.g., feeling hungry) $[134,135]$. The progression of CBT is concentrated on one new small change in food and exercise behavior (e.g., drinking water instead of soft drinks, walking instead of taking the car) $[135,136]$. Self-monitoring-recording one's behavior-is perhaps the most important component of behavioral treatment. Patients keep detailed records of their food intake, physical activity, and body weight, which they review with their interventionist to identify areas of success and for improvement [137].

Parents participate in CBT as helpers. For the stimulus control of the obese child, parents are taught the importance of ending restrictions on the places and times for eating. Motivation of the obese child is enhanced by allowing his or her own choices in planning the program and using a child-friendly approach with respect to developmental demands; for example, providing activities involving cooking, moving, and playing [134,135]. Braet and Van Winckel [135] reported that in the long-term follow-up over 4.6 years, $71.6 \%$ subjects treated with CBT showed no further increase in percentage overweight.

Negative body image is a major concern of overweight persons. CBT includes the information to change negative stereotypes of obesity, modification 
of intrusive thoughts of body dissatisfaction and overvalued beliefs regarding physical appearance, exposure to avoided body image situations, and elimination of body checking. CBT has significantly improved the body image, psychological symptoms, self-esteem, overeating, and guilt eating in obese subjects [138].

\section{Pharmacotherapy of children and adolescents with obesity}

7-1. We recommend that pharmacologic treatment is not used as a primary treatment nor sole therapy mode in pediatric obesity. (Strength of evidence, I; grade of recommendation, $\mathrm{A}$ )

$7-2$. We recommend that the response and adverse reaction to pharmacologic treatment be monitored closely. The decision to continue or discontinue should be made by accounting for the monitoring result. (Strength of evidence, V; grade of recommendation, A, based on committee voting)

7-1. We recommend that pharmacologic treatment not be used as a primary treatment nor lone therapy method in pediatric obesity. (Strength of evidence, l; grade of recommendation, A)

Only a few studies have been conducted in pharmacologic treatment for childhood obesity. In a pre-pubertal age group (younger than 12 years old), the effectiveness and safety of pharmacologic treatment of obesity are low because of issues of appropriate dosage, safety, adverse event, and ethical aspects $[139,140]$. Research data on adolescents over the age of 12 years are not sufficiently accumulated as well. However, some weight loss effects could be expected [139-141]. Therefore, in case of primary treatment failure, an approved drug could be considered added, along with behavioral intervention.

Orlistat, metformin, glucagon-like peptide 1 (GLP-1) agonists, and topiramate are available in adult obesity, and there have been a considerable number of efforts to use these agents in childhood obesity [142-146]. Orlistat is the only drug that the
FDA has approved for childhood obesity over the age of 12 years, but it is not recommended to use as a primary nor single therapy $[141,147]$. Data on the single drug use of orlistat without behavioral therapy are not available. In case of concerns on side effects, only behavioral therapy is recommended, instead of adding drugs.

1) Orlistat

Orlistat, a fat absorption inhibitor, is the only agent that the Korea Food and Drug Administration had approved for long-term use (one year) for weight control in pediatric obesity [148]. It is the only FDA-approved drug that can be prescribed three times a day for childhood obesity in children aged 12 to 16 years $[142,147]$. However, it is not recommended as a primary treatment for weight control in childhood obesity, especially between the ages of 2 and 11 years $[140,149]$. Orlistat inhibits lipid digestion by the suppression of pancreatic and gastric lipase. The decreased lipase activity in the gastrointestinal tract hinders consumed fat to be absorbed as a form of fatty acids and monoglycerols. Fat thus remains in the stool in triglyceride form [150]. A placebo controlled study of obese children aged 12 to 16 years showed a significant reduction in BMI compared with the controls, but also reported significant side effects. Another study among obese teenagers aged 14 to 18 years failed to show significant weight loss [151].

Orlistat should be taken with meals, which makes it difficult to prescribe to school-aged children. In some reports, orlistat interferes with the absorption of fat-soluble vitamins, such as vitamins $\mathrm{E}$ and D [141]. For many obesity-control drugs proven safe and effective for long-term use in adults, pediatric data are limited. Orlistat may cause adverse effects, such as steatorrhea, soiling, bloating, and increased number of bowel movement. Such adverse events have been reported in pediatric use. Younger patients are recommended to take multivitamins because orlistat can hinder the absorption of fat-soluble vitamins, such as vitamins $\mathrm{A}, \mathrm{K}$, and $\beta$-carotene. There have also been rare reports of hepatic and renal damage in adults, and of oxalate nephrolithiasis and 
oxalate nephropathy with renal failure [152].

2) Metformin

Metformin can be used safely in type 2 DM children over the age of 10 years and has been known to result in weight loss. It can be used at about 1,500 $\mathrm{mg}$ a day in children with type $2 \mathrm{DM}$ between the ages of 12 to 14 years with BMI of 26 to $40 \mathrm{~kg} / \mathrm{m}^{2}$ [153]. Although metformin can be used by type 2 DM children, it is not recommended as treatment for only obesity; indeed, it has not been FDA approved as an obesity treatment [154-156]. Metformin reduces hepatic glucose production, increases peripheral insulin sensitivity, and lowers appetite [157].

A study has shown BMI reduction after 6 to 12 months of use of metformin. A previous study reported that metformin has some effects in children with insulin resistance [158]. Although metformin could be used in the short term, along with behavioral therapy, it is not recommended as a single drug for obesity treatment because of the limited effect of weight control [11].

3) Liraglutide

Liraglutide is a GLP 1 analog that can be used for long-term treatment of adult obesity [11]. GLP-1 is the incretin hormone released by the ileal L-cells after food consumption, inducing satiety by delaying gastric emptying and glucagon secretion. It also controls appetite and satiety in the hypothalamus [141,149]. In adult type 2 DM, GLP-1 is an effective primary therapy for controlling HbAlc and weight. For obesity in adolescents, a significant decrease in BMI has been observed after three months of use [11,142].

Liraglutide needs to be injected daily, which can be a limitation in pediatric application. Safety and pharmacokinetics have been tested in children with type 2 DM aged between 10 and 17 years: it has similar effects as in adults. However, about half of the subjects experienced at least one side effect [159]. Among GLP-1's side effects are nausea, vomiting, diarrhea, and low blood glucoses. However, rare but serious side effects have also been reported, such as kidney failure, suicidal impulse, pancreatitis, and gallbladder disease [152]. Therefore, it is not recom- mended to use liraglutide for childhood obesity treatment.

\section{4) Topiramate}

Topiramate is a gamma-aminobutyric acid receptor antagonist that is known to be a treatment for epilepsy (for those aged 2 years and older) and migraine (for those aged 12 years and older). The weight loss effect of zonisamide (voltage-dependent sodium channels and T-type calcium blocker) was observed in the study of epilepsy, which might be related with the serotonin effect $[141,152,153]$. Despite the weight control effect of topiramate and zonisamide, the findings of epilepsy studies cannot be directly generalized into simple treatment for childhood obesity [149].

No proven safety or efficacy data are available with combined therapy of phentermine-topiramate in pediatric obesity [152]. The effect of zonisamide in pediatric obesity was reported in case reports of limited subjects [153]. Headache, nausea, vomiting, thirst, decreased appetite, abdominal pain, anxiety, speech disorders, attention and memory deficit, somnolence, and diarrhea have been associated with topiramate and zonisamide $[143,144,146]$. Serious side effects were reported in children using topiramate, such as glaucoma, stroke, metabolic acidosis, cognitive disorders, hyperammonianemia, encephalopathy, and kidney stone [152]. Therefore, it is not recommended to use topiramate for the treatment of childhood obesity.

7-2. We recommend that the response and adverse reaction of pharmacologic treatment be monitored closely. The decision to continue or discontinue treatment should be made with consideration for the monitoring result. (Strength of evidence, $V_{\text {; }}$ grade of recommendation, $A$, based on commiitte voting)

Although cumulative data on the effectiveness of pharmacologic treatment of childhood obesity are insufficient, reports of adverse reactions related to those agents exist in many references, including adults' studies $[11,141,150,152,160]$. Therefore, pharmacologic treatment of childhood obesity 
should be taken cautiously, and careful observation and evaluation of its adverse reactions and effects are essential.

\section{Bariatric surgery for children and adolescents with obesity}

8-1. We recommend that bariatric surgery be an appropriate option to improve health when adolescents with a BMI $>40 \mathrm{~kg} / \mathrm{m}^{2}$ or $>35 \mathrm{~kg} / \mathrm{m}^{2}$ and obesity-related comorbidities fail to respond to behavioral interventions (with or without pharmacotherapy) for sufficient weight loss to achieve targeted health outcome goals and when they attain Tanner 4 or 5 pubertal development and final or near-final adult height. (Strength of evidence, V; grade of recommendation, $\mathrm{A}$, based on committee voting)

The timing for surgical treatment of extremely obese adolescents remains controversial and depends, in most cases, on the compelling health needs of the patient [82]. Physiologic maturation is generally complete by sexual maturation (Tanner) stage 4. Bariatric surgery is considered only under the following conditions: when the patient has attained Tanner 4 or 5 pubertal development and final or near-final adult height, BMI $>35 \mathrm{~kg} / \mathrm{m}^{2}$ with major comorbidities (type $2 \mathrm{DM}$, moderate to severe sleep apnea of apnea-hypotonia index $>15$, pseudotumor cerebri, and severe non-alcoholic steatohepatitis) or BMI $>40 \mathrm{~kg} / \mathrm{m}^{2}$ with other comorbidities (hypertension, insulin resistance, glucose intolerance, dyslipidemia, sleep apnea with apnea-hypopnea index $>5$, and substantially impaired quality of life or activities of daily living). Skeletal maturation (adult stature) is normally attained by the age of 13 to 14 years in girls and 15 to 16 years in boys. If uncertainty exists on whether adult stature has been attained, skeletal maturation (bone age) can be objectively assessed with a radiograph of the hand and the wrist. From this view, bariatric surgery would not be recommended for pre-pubertal adolescents [161,162].
Adolescent psychological development also impacts the ability to participate in surgical decision-making and postoperative dietary compliance. Cognitive development refers to the development of the ability to think and reason [163].

\section{CONCLUSION}

This evidence-based clinical practice guideline on the diagnosis and treatment of pediatric obesity in children and adolescents in Korea was produced by all members of the Pediatric Obesity Committee of the KSPGHAN and experts from all related fields.

The most essential concept for the effective treatment of obesity in children and adolescents recommended in this guideline is a family-based, comprehensive, multidisciplinary behavioral intervention focused on lifestyle modification, including calorie-controlled balanced diet, active vigorous physical activity and exercise, and reduction of sedentary habits, and support by the entire family, school, and community. Evidence for the effectiveness and safety of most pharmacotherapy and bariatric surgery treatments remains limited in adolescents and insufficient in children.

For better outcomes, the prevention and treatment of obesity and obesity-related morbidity should be started from early in life to control and manage the risks for developing NAFLD, metabolic complications, and obesity-related physical and psychosocial comorbidities in childhood, and to reduce cardiovascular and metabolic morbidities and premature mortality later in adulthood as well. As the disease burden of obesity on the overall health status has become a key issue of health care system worldwide, including South Korea, this guideline would be beneficial not only in clinical practice but also in establishing health care policies.

\section{ACKNOWLEDGEMENTS}

The authors are grateful to the Korean Society for Pediatric Gastroenterology, Hepatology and Nutrition for the support to develop and publish this guideline. 


\section{REFERENCES}

1. Kang KS. Nutritional counseling for obese children with obesity-related metabolic abnormalities in Korea. Pediatr Gastroenterol Hepatol Nutr 2017;20: 71-8.

2. Yang HR, Yi DY, Choi HS. Comparison between a pediatric health promotion center and a pediatric obesity clinic in detecting metabolic syndrome and non-alcoholic fatty liver disease in children. J Korean Med Sci 2014;29:1672-7.

3. Atkins D, Best D, Briss PA, Eccles M, Falck-Ytter Y, Flottorp S, et al.; GRADE Working Group. Grading quality of evidence and strength of recommendations. BMJ 2004;328:1490.

4. Atkins D, Eccles M, Flottorp S, Guyatt GH, Henry D, Hill S, et al.; GRADE Working Group. Systems for grading the quality of evidence and the strength of recommendations I: critical appraisal of existing approaches the GRADE Working Group. BMC Health Serv Res 2004;4:38.

5. Guarino A, Albano F, Ashkenazi S, Gendrel D, Hoekstra JH, Shamir R, et al.; European Society for Paediatric Gastroenterology, Hepatology, and Nutrition; European Society for Paediatric Infectious Diseases. European Society for Paediatric Gastroenterology, Hepatology, and Nutrition/European Society for Paediatric Infectious Diseases evidence-based guidelines for the management of acute gastroenteritis in children in Europe. J Pediatr Gastroenterol Nutr 2008;46 Suppl 2:S81-122.

6. Kim JH, Yun S, Hwang SS, Shim JO, Chae HW, Lee YJ, et al; Committee for the Development of Growth Standards for Korean Children and Adolescents; Committee for School Health and Public Health Statistics, the Korean Pediatric Society; Division of Health and Nutrition Survey, Korea Centers for Disease Control and Prevention. The 2017 Korean National Growth Charts for children and adolescents: development, improvement, and prospects. Korean J Pediatr 2018;61:135-49.

7. Whitlock EP, O'Conner EA, Williams SB, Beil TL, Lutz KW. Effectiveness of primary care interventions for weight management in children and adolescents. Rockville (MD): Agency for Healthcare Research and Quality; 2010 Jan. Report No.: 10-05144-EF-1.

8. Barlow SE, Dietz WH. Obesity evaluation and treatment: Expert Committee recommendations. The Maternal and Child Health Bureau, Health Resources and Services Administration and the Department of Health and Human Services. Pediatrics 1998;102:E29.
9. Ogden CL, Kuczmarski RJ, Flegal KM, Mei Z, Guo S, Wei R, et al. Centers for Disease Control and Prevention 2000 growth charts for the United States: improvements to the 1977 National Center for Health Statistics version. Pediatrics 2002;109:45-60.

10. Javed A, Jumean M, Murad MH, Okorodudu D, Kumar S, Somers VK, et al. Diagnostic performance of body mass index to identify obesity as defined by body adiposity in children and adolescents: a systematic review and meta-analysis. Pediatr Obes 2015;10: 234-44.

11. Styne DM, Arslanian SA, Connor EL, Farooqi IS, Murad MH, Silverstein JH, et al. Pediatric obesity-assessment, treatment, and prevention: an Endocrine Society Clinical Practice Guideline. J Clin Endocrinol Metab 2017;102:709-57.

12. WHO Multicentre Growth Reference Study Group. WHO Child Growth Standards based on length/height, weight and age. Acta Paediatr Suppl 2006;450:76-85.

13. Freedman DS, Mei Z, Srinivasan SR, Berenson GS, Dietz WH. Cardiovascular risk factors and excess adiposity among overweight children and adolescents: the Bogalusa Heart Study. J Pediatr 2007;150: 12-7.e2.

14. Barlow SE; Expert Committee. Expert committee recommendations regarding the prevention, assessment, and treatment of child and adolescent overweight and obesity: summary report. Pediatrics 2007 ; 120 Suppl 4:S164-92.

15. Valerio G, Maffeis C, Saggese G, Ambruzzi MA, Balsamo A, Bellone S, et al. Diagnosis, treatment and prevention of pediatric obesity: consensus position statement of the Italian Society for Pediatric Endocrinology and Diabetology and the Italian Society of Pediatrics. Ital J Pediatr 2018;44:88.

16. de Onis M, Onyango AW, Borghi E, Siyam A, Nishida C, Siekmann J. Development of a WHO growth reference for school-aged children and adolescents. Bull World Health Organ 2007;85:660-7.

17. American Diabetes Association. Diagnosis and classification of diabetes mellitus. Diabetes Care 2014;37 Suppl 1:S81-90.

18. Expert Panel on Integrated Guidelines for Cardiovascular Health and Risk Reduction in Children and Adolescents; National Heart, Lung, and Blood Institute. Expert panel on integrated guidelines for cardiovascular health and risk reduction in children and adolescents: summary report. Pediatrics 2011;128 Suppl 5:S213-56.

19. Schwimmer JB, Dunn W, Norman GJ, Pardee PE, Middleton MS, Kerkar N, et al. SAFETY study: ala- 
nine aminotransferase cutoff values are set too high for reliable detection of pediatric chronic liver disease. Gastroenterology 2010;138:1357-64, 1364.e1-2.

20. Legro RS, Arslanian SA, Ehrmann DA, Hoeger KM, Murad MH, Pasquali R, et al. Diagnosis and treatment of polycystic ovary syndrome: an Endocrine Society clinical practice guideline. J Clin Endocrinol Metab 2013;98:4565-92.

21. Wise MS, Nichols CD, Grigg-Damberger MM, Marcus CL, Witmans MB, Kirk VG, et al. Executive summary of respiratory indications for polysomnography in children: an evidence-based review. Sleep 2011;34: 389-98AW.

22. Zametkin AJ, Zoon CK, Klein HW, Munson S. Psychiatric aspects of child and adolescent obesity: a review of the past 10 years. J Am Acad Child Adolesc Psychiatry 2004;43:134-50.

23. Spear BA, Barlow SE, Ervin C, Ludwig DS, Saelens $\mathrm{BE}$, Schetzina KE, et al. Recommendations for treatment of child and adolescent overweight and obesity. Pediatrics 2007;120 Suppl 4:S254-88.

24. Rhee KE, Lumeng JC, Appugliese DP, Kaciroti N, Bradley RH. Parenting styles and overweight status in first grade. Pediatrics 2006;117:2047-54.

25. Zeller MH, Reiter-Purtill J, Ramey C. Negative peer perceptions of obese children in the classroom environment. Obesity (Silver Spring) 2008;16:755-62.

26. Fox CL, Farrow CV. Global and physical self-esteem and body dissatisfaction as mediators of the relationship between weight status and being a victim of bullying. J Adolesc 2009;32:1287-301.

27. Koval JJ, Pederson LL, Zhang X, Mowery P, McKenna M. Can young adult smoking status be predicted from concern about body weight and self-reported BMI among adolescents? Results from a ten-year cohort study. Nicotine Tob Res 2008;10:1449-55.

28. Pearce MJ, Boergers J, Prinstein MJ. Adolescent obesity, overt and relational peer victimization, and romantic relationships. Obes Res 2002;10:386-93.

29. Rajjo T, Mohammed K, Alsawas M, Ahmed AT, Farah W, Asi N, et al. Treatment of pediatric obesity: an umbrella systematic review. J Clin Endocrinol Metab 2017;102:763-75.

30. Mcmurray RG, Harrell JS, Bangdiwala SI, Bradley CB, Deng S, Levine A. A school-based intervention can reduce body fat and blood pressure in young adolescents. J Adolesc Health 2002;31:125-32.

31. Sallis JF, Conway TL, Prochaska JJ, McKenzie TL, Marshall SJ, Brown M. The association of school environments with youth physical activity. Am J Public Health 2001;91:618-20.
32. te Velde SJ, van Nassau F, Uijtdewilligen L, van Stralen MM, Cardon G, De Craemer M, et al. Energy balance-related behaviours associated with overweight and obesity in preschool children: a systematic review of prospective studies. Obes Rev 2012;13 Suppl 1:56-74.

33. Epstein LH, Roemmich JN, Robinson JL, Paluch RA, Winiewicz DD, Fuerch JH, et al. A randomized trial of the effects of reducing television viewing and computer use on body mass index in young children. Arch Pediatr Adolesc Med 2008;162:239-45.

34. Steffen LM, Sinaiko AR, Zhou X, Moran A, Jacobs DR Jr, Korenfeld Y, et al. Relation of adiposity, television and screen time in offspring to their parents. BMC Pediatr 2013;13:133.

35. Edwards C, Nicholls D, Croker H, Van Zyl S, Viner R, Wardle J. Family-based behavioural treatment of obesity: acceptability and effectiveness in the UK. Eur J Clin Nutr 2006;60:587-92.

36. Schalkwijk AA, Bot SD, de Vries L, Westerman MJ, Nijpels G, Elders PJ. Perspectives of obese children and their parents on lifestyle behavior change: a qualitative study. Int J Behav Nutr Phys Act 2015;12:102.

37. Munding E, Ponniah K, Stephen G, Weedn A. The Oklahoma Chapter AAP obesity provider and parent handouts: tools to encourage lifestyle changes to manage and prevent pediatric obesity. Pediatrics 2018; 141:MeetingAbstract. Available from: http://pediatrics. aappublications.org/content/141/1_MeetingAbstract/ 00.2..info.

38. US Preventive Services Task Force, Grossman DC, Bibbins-Domingo K, Curry SJ, Barry MJ, Davidson KW, et al. Screening for obesity in children and adolescents: US Preventive Services Task Force Recommendation Statement. JAMA 2017;317:2417-26.

39. Speiser PW, Rudolf MC, Anhalt H, Camacho-Hubner C, Chiarelli F, Eliakim A, et al; Obesity Consensus Working Group. Childhood obesity. J Clin Endocrinol Metab 2005;90:1871-87.

40. Sherafat-Kazemzadeh R, Yanovski SZ, Yanovski JA. Pharmacotherapy for childhood obesity: present and future prospects. Int J Obes (Lond) 2013;37:1-15.

41. Nobili V, Vajro P, Dezsofi A, Fischler B, Hadzic N, Jahnel J, et al. Indications and limitations of bariatric intervention in severely obese children and adolescents with and without nonalcoholic steatohepatitis: ESPGHAN Hepatology Committee Position Statement. J Pediatr Gastroenterol Nutr 2015;60:550-61.

42. Michalsky M, Reichard K, Inge T, Pratt J, Lenders C; American Society for Metabolic and Bariatric Surgery. ASMBS pediatric committee best practice 
guidelines. Surg Obes Relat Dis 2012;8:1-7.

43. Lee HS, Kwon SO, Lee Y. Weight status and dietary factors associated with sugar-sweetened beverage intake among Korean children and adolescents - Korea National Health and Nutrition Examination Survey, 2008-2011. Clin Nutr Res 2013;2:135-42.

44. Ebbeling CB, Feldman HA, Osganian SK, Chomitz VR, Ellenbogen SJ, Ludwig DS. Effects of decreasing sugar-sweetened beverage consumption on body weight in adolescents: a randomized, controlled pilot study. Pediatrics 2006;117:673-80.

45. Ebbeling CB, Feldman HA, Chomitz VR, Antonelli TA, Gortmaker SL, Osganian SK, et al. A randomized trial of sugar-sweetened beverages and adolescent body weight. N Engl J Med 2012;367:1407-16.

46. DeBoer MD, Scharf RJ, Demmer RT. Sugar-sweetened beverages and weight gain in 2- to 5-year-old children. Pediatrics 2013;132:413-20.

47. Frantsve-Hawley J, Bader JD, Welsh JA, Wright JT. A systematic review of the association between consumption of sugar-containing beverages and excess weight gain among children under age 12. J Public Health Dent 2017;77 Suppl 1:S43-66.

48. Kosova EC, Auinger P, Bremer AA. The relationships between sugar-sweetened beverage intake and cardiometabolic markers in young children. J Acad Nutr Diet 2013;113:219-27.

49. Gow ML, Ho M, Burrows TL, Baur LA, Stewart L, Hutchesson MJ, et al. Impact of dietary macronutrient distribution on BMI and cardiometabolic outcomes in overweight and obese children and adolescents: a systematic review. Nutr Rev 2014;72:453-70.

50. Thomas DE, Elliott EJ, Baur L. Low glycaemic index or low glycaemic load diets for overweight and obesity. Cochrane Database Syst Rev 2007;(3):CD005105.

51. Schwingshackl L, Hobl LP, Hoffmann G. Effects of low glycaemic index/low glycaemic load vs. high glycaemic index/ high glycaemic load diets on overweight/obesity and associated risk factors in children and adolescents: a systematic review and meta-analysis. Nutr J 2015;14:87.

52. Ochiai H, Shirasawa T, Nanri H, Nishimura R, Hoshino H, Kokaze A. Relationship between eating quickly and overweight: a cohort study of schoolchildren in Japan. Acta Med Okayama 2018;72:121-8.

53. Ochiai H, Shirasawa T, Ohtsu T, Nishimura R, Morimoto A, Hoshino H, et al. The impact of eating quickly on anthropometric variables among schoolgirls: a prospective cohort study in Japan. Eur J Public Health 2014;24:691-5.

54. Costa S, Pinto A, Santos AC, Oliveira A. The associa- tion of problematic eating behaviours with food quality and body mass index at 7 years of age. Eur J Clin Nutr 2018. doi: 10.1038/s41430-018-0169-z. [Epub ahead of print]

55. Timlin MT, Pereira MA, Story M, Neumark-Sztainer D. Breakfast eating and weight change in a 5-year prospective analysis of adolescents: project EAT (Eating Among Teens). Pediatrics 2008;121:e638-45.

56. Croezen S, Visscher TL, Ter Bogt NC, Veling ML, Haveman-Nies A. Skipping breakfast, alcohol consumption and physical inactivity as risk factors for overweight and obesity in adolescents: results of the E-MOVO project. Eur J Clin Nutr 2009;63:405-12.

57. Brown AW, Bohan Brown MM, Allison DB. Belief beyond the evidence: using the proposed effect of breakfast on obesity to show 2 practices that distort scientific evidence. Am J Clin Nutr 2013;98:1298-308.

58. Arora M, Nazar GP, Gupta VK, Perry CL, Reddy KS, Stigler MH. Association of breakfast intake with obesity, dietary and physical activity behavior among urban school-aged adolescents in Delhi, India: results of a cross-sectional study. BMC Public Health 2012;12: 881.

59. Bayer O, Nehring I, Bolte G, von Kries R. Fruit and vegetable consumption and BMI change in primary school-age children: a cohort study. Eur J Clin Nutr 2014;68:265-70.

60. Bontrager Yoder AB, Schoeller DA. Fruits and vegetables displace, but do not decrease, total energy in school lunches. Child Obes 2014;10:357-64.

61. Kral TV, Rolls BJ. Energy density and portion size: their independent and combined effects on energy intake. Physiol Behav 2004;82:131-8.

62. Hollands GJ, Shemilt I, Marteau TM, Jebb SA, Lewis HB, Wei Y, et al. Portion, package or tableware size for changing selection and consumption of food, alcohol and tobacco. Cochrane Database Syst Rev 2015;(9):CD011045.

63. Fisher JO, Liu Y, Birch LL, Rolls BJ. Effects of portion size and energy density on young children's intake at a meal. Am J Clin Nutr 2007;86:174-9.

64. McConahy KL, Smiciklas-Wright H, Mitchell DC, Picciano MF. Portion size of common foods predicts energy intake among preschool-aged children. J Am Diet Assoc 2004;104:975-9.

65. Torbahn G, Gellhaus I, Koch B, von Kries R, Obermeier V, Holl RW, et al. Reduction of portion size and eating rate is associated with BMI-SDS reduction in overweight and obese children and adolescents: results on eating and nutrition behaviour from the Observational KgAS Study. Obes Facts 2017;10: 
503-16.

66. Braithwaite I, Stewart AW, Hancox RJ, Beasley R, Murphy R, Mitchell EA; ISAAC Phase Three Study Group; ISAAC Phase Three Study Group. Fast-food consumption and body mass index in children and adolescents: an international cross-sectional study. BMJ Open 2014;4:e005813.

67. Niemeier HM, Raynor HA, Lloyd-Richardson EE, Rogers ML, Wing RR. Fast food consumption and breakfast skipping: predictors of weight gain from adolescence to adulthood in a nationally representative sample. J Adolesc Health 2006;39:842-9.

68. Lee JW, Hwang J, Cho HS. Dietary patterns of children and adolescents analyzed from 2001 Korea National Health and Nutrition Survey. Nutr Res Pract 2007;1:84-8.

69. Park EH, Oh MS, Kim S, Lee J, Kang KS. The analysis of factors causing the high prevalence of child obesity in Jeju Island. Pediatr Gastroenterol Hepatol Nutr 2018;21:127-33.

70. Martin A, Booth JN, Laird Y, Sproule J, Reilly JJ, Saunders DH. Physical activity, diet and other behavioural interventions for improving cognition and school achievement in children and adolescents with obesity or overweight. Cochrane Database Syst Rev 2018;3:CD009728.

71. Pate RR, Davis MG, Robinson TN, Stone EJ, McKenzie TL, Young JC; American Heart Association Council on Nutrition, Physical Activity, and Metabolism (Physical Activity Committee); Council on Cardiovascular Disease in the Young; Council on Cardiovascular Nursing. Promoting physical activity in children and youth: a leadership role for schools: a scientific statement from the American Heart Association Council on Nutrition, Physical Activity, and Metabolism (Physical Activity Committee) in collaboration with the Councils on Cardiovascular Disease in the Young and Cardiovascular Nursing. Circulation 2006;114:1214-24.

72. Kim KB, Lim KI, So WY, Park SK, Song W. A meta-analysis of the effects of exercise therapy applied in obesity studies. Korean J Obes 2007;16: 177-85.

73. Lee DC, Pate RR, Lavie CJ, Sui X, Church TS, Blair $\mathrm{SN}$. Leisure-time running reduces all-cause and cardiovascular mortality risk. J Am Coll Cardiol 2014; 64:472-81.

74. Bidzan-Bluma I, Lipowska M. Physical activity and cognitive functioning of children: a systematic review. Int J Environ Res Public Health 2018;15:800.

75. Davis CL, Tomporowski PD, McDowell JE, Austin BP,
Miller PH, Yanasak NE, et al. Exercise improves executive function and achievement and alters brain activation in overweight children: a randomized, controlled trial. Health Psychol 2011;30:91-8.

76. Mead E, Brown T, Rees K, Azevedo LB, Whittaker V, Jones D, et al. Diet, physical activity and behavioural interventions for the treatment of overweight or obese children from the age of 6 to 11 years. Cochrane Database Syst Rev 2017;6:CD012651.

77. Oude Luttikhuis H, Baur L, Jansen H, Shrewsbury VA, O'Malley C, Stolk RP, et al. Interventions for treating obesity in children. Cochrane Database Syst Rev 2009;(1):CD001872.

78. Strahan BE, Ahn H, Shuster J. Meta-analysis of the effects of exercise interventions on obese adolescents. J Nurs Interprof Leadersh Qual Saf 2018;2. Available from: https://digitalcommons.library.tmc.edu/uthoustonjqualsafe/vol2/iss1/1.

79. Katzmarzyk PT, Denstel KD, Beals K, Bolling C, Wright C, Crouter SE, et al. Results from the United States of America's 2016 report card on physical activity for children and youth. J Phys Act Health 2016;13(11 Suppl 2):S307-13.

80. Piekarz E, Schermbeck R, Young SK, Leider J, Ziemann M, Chriqui JF. School district wellness policies: evaluating progress and potential for improving children's health eight years after the federal mandate. School years 2006-07 through 2013-14. Chicago, IL: Bridging the Gap Program and the National Wellness Policy Study; 2016.

81. Ismail I, Keating SE, Baker MK, Johnson NA. A systematic review and meta-analysis of the effect of aerobic vs. resistance exercise training on visceral fat. Obes Rev 2012;13:68-91.

82. Peirson L, Fitzpatrick-Lewis D, Morrison K, Warren R, Usman Ali M, Raina P. Treatment of overweight and obesity in children and youth: a systematic review and meta-analysis. CMAJ Open 2015;3:E35-46.

83. Farias Edos S, Gonçalves EM, Morcillo AM, GuerraJúnior G, Amancio OM. Effects of programmed physical activity on body composition in post-pubertal schoolchildren. J Pediatr (Rio J) 2015;91:122-9.

84. Baek S. The effect of physical activity on children's obesity. Korean J Obes 2008;17:55-64.

85. Kim HG, Nam HK. A survey of life style habits of obese school children. J Korean Soc School Health 1998; 11:99-110.

86. Lee YJ, Chang KJ. A comparative study of obese children and normal children on dietary intake and environmental factors at an elementary school in Inchon. Korean J Community Nutr 1999;4:504-11. 
87. Kim BS, Lee KA. Comparisons of the daily activities and energy expenditures of normally-weighted and obese elementary school children. Korean J Nutr 2005;38:847-55.

88. Park DK, Kang EH. A comparative study on the attitudes toward physical education as related to a degree of obesity in elementary students. J Korean Soc Study Phys Educ 1996;1:109-24.

89. Kim MS, Choi JH, Shin HC, Joo KJ, Yoo YJ, Ko HJ, et al. Association of TV viewing and computer using habits with obesity and obesity related lifestyles. J Korean Acad Fam Med 2008;29:182-8.

90. Kim SH, Lee SH, Chun JY, Cho YG, Kim YH, Kim MJ, et al. Relationship between physical activity, dietary habits and overweight of 7-year-old Korean children. J Korean Acad Fam Med 2007;28:195-203.

91. Park JB, Choi TI, Kim JS, Jung DS, Kim KN, Lee SY, et al. The prevalence of childhood obesity, risk factors, and obesity related disease in elementary students. J Korean Acad Fam Med 2006;27:104-12.

92. Rey-López JP, Vicente-Rodríguez G, Biosca M, Moreno LA. Sedentary behaviour and obesity development in children and adolescents. Nutr Metab Cardiovasc Dis 2008;18:242-51.

93. Salmon J, Campbell KJ, Crawford DA. Television viewing habits associated with obesity risk factors: a survey of Melbourne schoolchildren. Med J Aust 2006;184:64-7.

94. Coon KA, Goldberg J, Rogers BL, Tucker KL. Relationships between use of television during meals and children's food consumption patterns. Pediatrics 2001;107:E7.

95. Zabinski MF, Norman GJ, Sallis JF, Calfas KJ, Patrick K. Patterns of sedentary behavior among adolescents. Health Psychol 2007;26:113-20.

96. Grimm GC, Harnack L, Story M. Factors associated with soft drink consumption in school-aged children. J Am Diet Assoc 2004;104:1244-9.

97. Lee BH, Kang SG, Choi JW, Lee YJ. The association between self-reported sleep duration and body mass index among Korean adolescents. J Korean Med Sci 2016;31:1996-2001.

98. Kam H, Kagn M, Youn J, Park J, Cha Y, Yu Y, et al. Association between sleep duration and obesity in Korean adolescents: the 6th Korea National Health and Nutrition Examination Survey (2013-2014). Korean J Fam Pract 2017;7:625-32.

99. Sekine M, Yamagami T, Handa K, Saito T, Nanri S, Kawaminami K, et al. A dose-response relationship between short sleeping hours and childhood obesity: results of the Toyama Birth Cohort Study. Child Care
Health Dev 2002;28:163-70.

100. Jiang F, Zhu S, Yan C, Jin X, Bandla H, Shen X. Sleep and obesity in preschool children. J Pediatr 2009; 154:814-8.

101. Chaput JP, Brunet M, Tremblay A. Relationship between short sleeping hours and childhood overweight/obesity: results from the 'Québec en Forme' Project. Int J Obes (Lond) 2006;30:1080-5.

102. Felsố R, Lohner S, Hollódy K, Erhardt É, Molnár D. Relationship between sleep duration and childhood obesity: systematic review including the potential underlying mechanisms. Nutr Metab Cardiovasc Dis 2017;27:751-61.

103. Hart CN, Carskadon MA, Considine RV, Fava JL, Lawton J, Raynor HA, et al. Changes in children's sleep duration on food intake, weight, and leptin. Pediatrics 2013;132:e1473-80.

104. Chaput JP, Katzmarzyk PT, LeBlanc AG, Tremblay MS, Barreira TV, Broyles ST, et al. Associations between sleep patterns and lifestyle behaviors in children: an international comparison. Int J Obes Suppl 2015;5(Suppl 2):S59-65.

105. Kjeldsen JS, Hjorth MF, Andersen R, Michaelsen KF, Tetens I, Astrup A, et al. Short sleep duration and large variability in sleep duration are independently associated with dietary risk factors for obesity in Danish school children. Int J Obes (Lond) 2014;38:32-9.

106. Berge JM, Everts JC. Family-based interventions targeting childhood obesity: a meta-analysis. Child Obes 2011;7:110-21.

107. Kim SW, Cho YG, Kang JH, Lee SH, Lee JE, Park HA, et al. The relationships between parental lifestyle habits and children's overweight. J Korean Acad Fam Med 2008;29:395-404.

108. Lee HS, Duffey KJ, Kim CI, Popkin BM. The relationship between family and child weight status by household structure in South Korea: 2007-2010. Nutr Diabetes 2013;3:e73.

109. Wu S, Ding Y, Wu F, Li R, Hu Y, Hou J, et al. Socio-economic position as an intervention against overweight and obesity in children: a systematic review and meta-analysis. Sci Rep 2015;5:11354.

110. Barriuso L, Miqueleiz E, Albaladejo R, Villanueva R, Santos JM, Regidor E. Socioeconomic position and childhood-adolescent weight status in rich countries: a systematic review, 1990-2013. BMC Pediatr 2015; 15:129.

111. Jang HB, Park JY, Lee HJ, Kang JH, Park KH, Song J. Association between parental socioeconomic level, overweight, and eating habits with diet quality in Korean sixth grade school children. Korean J Nutr 
2011;44:416-27.

112. Höglund D, Samuelson G, Mark A. Food habits in Swedish adolescents in relation to socioeconomic conditions. Eur J Clin Nutr 1998;52:784-9.

113. Abudayya AH, Stigum H, Shi Z, Abed Y, HolmboeOttesen G. Sociodemographic correlates of food habits among school adolescents (12-15 year) in North Gaza Strip. BMC Public Health 2009;9:185.

114. Samuelson G. Dietary habits and nutritional status in adolescents over Europe. An overview of current studies in the Nordic countries. Eur J Clin Nutr 2000;54 Suppl 1:S21-8.

115. Park J, Ma H, Lee YN, Oh H. Trends in intervention study for childhood obesity in Korea. Child Health Nurs Res 2017;23:81-90.

116. Waters E, de Silva-Sanigorski A, Hall BJ, Brown T, Campbell KJ, Gao Y, et al. Interventions for preventing obesity in children. Cochrane Database Syst Rev 2011;7:CD001871.

117. Samuels SE, Craypo L, Boyle M, Crawford PB, Yancey A, Flores G. The California Endowment's Healthy Eating, Active Communities program: a midpoint review. Am J Public Health 2010;100:2114-23.

118. Power TG, Bindler RC, Goetz S, Daratha KB. Obesity prevention in early adolescence: student, parent, and teacher views. J Sch Health 2010;80:13-9.

119. Griffiths LJ, Parsons TJ, Hill AJ. Self-esteem and quality of life in obese children and adolescents: a systematic review. Int J Pediatr Obes 2010;5:282-304.

120. Rankin J, Matthews L, Cobley S, Han A, Sanders R, Wiltshire HD, et al. Psychological consequences of childhood obesity: psychiatric comorbidity and prevention. Adolesc Health Med Ther 2016;7:125-46.

121. Kwak YS, Shin JH, Kang KS, Jung YE, Kim MD. Prevalence of high risk for eating disorder and its correlates in children and adolescents: focus on body image distortion. Mood Emot 2013;11:195-201.

122. Kang NR, Lee JS, Kang KS, Kwack YS. Mental health problems in child and adolescent obesity. J Korean Acad Child Adolesc Psychiatry 2016;27:119-29.

123. Van Vlierberghe L, Braet C, Goossens L, Mels S. Psychiatric disorders and symptom severity in referred versus non-referred overweight children and adolescents. Eur Child Adolesc Psychiatry 2009;18: 164-73.

124. McClure AC, Tanski SE, Kingsbury J, Gerrard M, Sargent JD. Characteristics associated with low self-esteem among US adolescents. Acad Pediatr 2010;10:238-44.e2.

125. Nowicka P, Höglund P, Birgerstam P, Lissau I, Pietrobelli A, Flodmark CE. Self-esteem in a clinical sample of morbidly obese children and adolescents. Acta Paediatr 2009;98:153-8.

126. Varni JW, Limbers CA, Burwinkle TM. Impaired health-related quality of life in children and adolescents with chronic conditions: a comparative analysis of 10 disease clusters and 33 disease categories/severities utilizing the PedsQL 4.0 Generic Core Scales. Health Qual Life Outcomes 2007;5:43.

127. Schwimmer JB, Burwinkle TM, Varni JW. Health-related quality of life of severely obese children and adolescents. JAMA 2003;289:1813-9.

128. Britz B, Siegfried W, Ziegler A, Lamertz C, HerpertzDahlmann BM, Remschmidt H, et al. Rates of psychiatric disorders in a clinical study group of adolescents with extreme obesity and in obese adolescents ascertained via a population based study. Int J Obes Relat Metab Disord 2000;24:1707-14.

129. McLean N, Griffin S, Toney K, Hardeman W. Family involvement in weight control, weight maintenance and weight-loss interventions: a systematic review of randomised trials. Int J Obes Relat Metab Disord 2003;27:987-1005.

130. Halliday JA, Palma CL, Mellor D, Green J, Renzaho AM. The relationship between family functioning and child and adolescent overweight and obesity: a systematic review. Int J Obes (Lond) 2014;38:480-93.

131. Shin JA, Bae SP, Kim HS, Park HS. Psychosocial factors and familial environments in adolescent obesity. J Korean Acad Fam Med 2002;23:1024-32.

132. Gibson LY, Byrne SM, Davis EA, Blair E, Jacoby P, Zubrick SR. The role of family and maternal factors in childhood obesity. Med J Aust 2007;186:591-5.

133. Oh MS, Kim S, Jang JH, Park JY, Kang HS, Lee MS, et al. Associations among the degree of Nonalcoholic fatty liver disease, metabolic syndrome, degree of obesity in children, and parental obesity. Pediatr Gastroenterol Hepatol Nutr 2016;19:199-206.

134. Braet C, Van Winckel M, Van Leeuwen K. Follow-up results of different treatment programs for obese children. Acta Paediatr 1997;86:397-402.

135. Braet C, Van Winckel M. Long-term follow-up of a cognitive behavioral treatment program for obese children. Behav Ther 2000;31:55-74.

136. Flodmark CE, Lissau I, Moreno LA, Pietrobelli A, Widhalm K. New insights into the field of children and adolescents' obesity: the European perspective. Int J Obes Relat Metab Disord 2004;28:1189-96.

137. Wadden TA, Butryn ML, Wilson C. Lifestyle modification for the management of obesity. Gastroenterology 2007;132:2226-38.

138. Rosen JC, Orosan P, Reiter J. Cognitive behavior ther- 
apy for negative body image in obese women. Behav Ther 1995;26:25-42.

139. Mead E, Atkinson G, Richter B, Metzendorf MI, Baur L, Finer N, et al. Drug interventions for the treatment of obesity in children and adolescents. Cochrane Database Syst Rev 2016;11:CD012436.

140. Parkin P, Connor Gorber S, Shaw E, Bell N, Jaramillo A, Tonelli M, et al. Recommendations for growth monitoring, and prevention and management of overweight and obesity in children and youth in primary care. CMAJ 2015;187:411-21.

141. Shettar V, Patel S, Kidambi S. Epidemiology of obesity and pharmacologic treatment options. Nutr Clin Pract 2017;32:441-62.

142. Kelly AS, Rudser KD, Nathan BM, Fox CK, Metzig AM, Coombes BJ, et al. The effect of glucagon-like peptide-1 receptor agonist therapy on body mass index in adolescents with severe obesity: a randomized, placebo-controlled, clinical trial. JAMA Pediatr 2013;167: 355-60.

143. Ryder JR, Kaizer A, Rudser KD, Gross A, Kelly AS, Fox CK. Effect of phentermine on weight reduction in a pediatric weight management clinic. Int J Obes (Lond) 2017;41:90-3.

144. Fox CK, Kaizer AM, Rudser KD, Nathan BM, Gross AC, Sunni M, et al. Meal replacements followed by topiramate for the treatment of adolescent severe obesity: a pilot randomized controlled trial. Obesity (Silver Spring) 2016;24:2553-61.

145. Chanoine JP, Hampl S, Jensen C, Boldrin M, Hauptman J. Effect of orlistat on weight and body composition in obese adolescents: a randomized controlled trial. JAMA 2005;293:2873-83.

146. Yanovski JA, Krakoff J, Salaita CG, McDuffie JR, Kozlosky M, Sebring NG, et al. Effects of metformin on body weight and body composition in obese insulin-resistant children: a randomized clinical trial. Diabetes 2011;60:477-85.

147. Maahs D, de Serna DG, Kolotkin RL, Ralston S, Sandate J, Qualls C, et al. Randomized, double-blind, placebo-controlled trial of orlistat for weight loss in adolescents. Endocr Pract 2006;12:18-28.

148. Kim MK, Lee WY, Kang JH, Kang JH, Kim BT, Kim SM, et al. 2014 clinical practice guidelines for overweight and obesity in Korea. Endocrinol Metab (Seoul) 2014;29:405-9.

149. O'Connor EA, Evans CV, Burda BU, Walsh ES, Eder M, Lozano P. Screening for obesity and intervention for weight management in children and adolescents: evidence report and systematic review for the US Preventive Services Task Force. JAMA 2017;317:
2427-44.

150. Heck AM, Yanovski JA, Calis KA. Orlistat, a new lipase inhibitor for the management of obesity. Pharmacotherapy 2000;20:270-9.

151. Czernichow S, Lee CM, Barzi F, Greenfield JR, Baur LA, Chalmers J, et al. Efficacy of weight loss drugs on obesity and cardiovascular risk factors in obese adolescents: a meta-analysis of randomized controlled trials. Obes Rev 2010;11:150-8.

152. Chao AM, Wadden TA, Berkowitz RI. The safety of pharmacologic treatment for pediatric obesity. Expert Opin Drug Saf 2018;17:379-85.

153. Boland CL, Harris JB, Harris KB. Pharmacological management of obesity in pediatric patients. Ann Pharmacother 2015;49:220-32.

154. Lenders CM, Gorman K, Lim-Miller A, Puklin S, Pratt J. Practical approaches to the treatment of severe pediatric obesity. Pediatr Clin North Am 2011;58: 1425-38, x-xi.

155. Atabek ME, Pirgon O. Use of metformin in obese adolescents with hyperinsulinemia: a 6 -month, randomized, double-blind, placebo-controlled clinical trial. J Pediatr Endocrinol Metab 2008;21:339-48.

156. Kendall D, Vail A, Amin R, Barrett T, Dimitri P, Ivison F, et al. Metformin in obese children and adolescents: the MOCA trial. J Clin Endocrinol Metab 2013;98: 322-9.

157. Adeyemo MA, McDuffie JR, Kozlosky M, Krakoff J, Calis KA, Brady SM, et al. Effects of metformin on energy intake and satiety in obese children. Diabetes Obes Metab 2015;17:363-70.

158. Wiegand S, l'Allemand D, Hübel H, Krude H, Bürmann M, Martus P, et al. Metformin and placebo therapy both improve weight management and fasting insulin in obese insulin-resistant adolescents: a prospective, placebo-controlled, randomized study. Eur J Endocrinol 2010;163:585-92.

159. Danne T, Biester T, Kapitzke K, Jacobsen SH, Jacobsen LV, Petri KCC, et al. Liraglutide in an adolescent population with obesity: a randomized, double-blind, placebo-controlled 5-week trial to assess safety, tolerability, and pharmacokinetics of liraglutide in adolescents aged 12-17 years. J Pediatr 2017; 181:146-153.e3.

160. Davidson MH, Hauptman J, DiGirolamo M, Foreyt JP, Halsted CH, Heber D, et al. Weight control and risk factor reduction in obese subjects treated for 2 years with orlistat: a randomized controlled trial. JAMA 1999;281:235-42.

161. O'Brien PE, Sawyer SM, Laurie C, Brown WA, Skinner S, Veit F, et al. Laparoscopic adjustable gas- 
tric banding in severely obese adolescents: a randomized trial. JAMA 2010;303:519-26.

162. Jensen MD, Ryan DH, Apovian CM, Ard JD, Comuzzie AG, Donato KA, et al. 2013 AHA/ACC/TOS guideline for the management of overweight and obesity in adults: a report of the American College of Cardiology/ American Heart Association Task Force on Practice
Guidelines and The Obesity Society. J Am Coll Cardiol 2014;63:2985-3023.

163. Kushner RF, Ryan DH. Assessment and lifestyle management of patients with obesity: clinical recommendations from systematic reviews. JAMA 2014; 312:943-52. 